\title{
La valoración del patrimonio geológico y paleontológico como herramienta de gestión: el Modelo FOPALI
}

\author{
Esteban José SÁNCHEZ-FERRIS ${ }^{*}$, Ignacio FIERRO-BANDERA2, Ainara ABERASTURI- \\ RODRÍGUEZ ${ }^{1,2}$, José NAVARRO-PEDREÑO ${ }^{3}$ \& Plinio MONTOYA-BELLÓ ${ }^{4}$
}

\footnotetext{
${ }^{1}$ Museo Paleontológico de Elche (MUPE), Plaza San Juan, 03203 Elche, Alicante; appalser@yahoo.es; ainara@cidarismpe.org

${ }^{2}$ GeaLand Patrimonio S.L., C/. Tibi no 3, 03010 Alicante; fierro@gealandpatrimonio.com; ainara@gealandpatrimonio.com

${ }^{3}$ Departamento de Agroquímica y Medio Ambiente, Universidad Miguel Hernández de Elche, Edificio Alcudia, Avenida Universidad s/n, 03202 Elche, Alicante; jonavar@uhm.es

${ }^{4}$ Departament de Botànica i Geologia, Universitat de València, Doctor Moliner 50, 46100, Burjassot, Valencia; pmontoya@uv.es

* Corresponding author
}

Sánchez-Ferris, E.J., Fierro-Bandera, I., Aberasturi-Rodríguez, A., Navarro-Pedreño, J. \& Montoya-Belló, P. 2019. La valoración del patrimonio geológico y paleontológico como herramienta de gestión: el Modelo FOPALI. [Geological and palaeontological heritage assessment as a management tool: FOPALI Project methodology]. Spanish Journal of Palaeontology, 34 (1), 35-56.

\section{RESUMEN}

El compromiso con la preservación del patrimonio geológico y paleontológico ha constituido una prioridad para el Museo Paleontológico de Elche - Fundación Cidaris desde los inicios de su actividad. En este contexto se ha desarrollado una estrategia de trabajo (FOPALI) en el que la valoración patrimonial es concebida como una herramienta de gestión. Se exponen aquí las bases metodológicas del modelo FOPALI y las técnicas de análisis aplicadas para ofrecer a los gestores del patrimonio la información necesaria para establecer prioridades en la investigación, conservación y difusión del patrimonio geológico y paleontológico.

Palabras clave: Patrimonio geológico y paleontológico, valoración patrimonial, gestión patrimonial.

\begin{abstract}
Absolute commitment to palaeontological and geological heritage preservation has always been a priority for the Palaeontological Museum of Elche (MUPE)-Cidaris Foundation. It is in this context that a work strategy in which heritage assessment is conceived as a management tool has been developed: FOPALI. Its methodological bases and applied analysis techniques are exposed here. FOPALI model has been designed to provide a guideline to help heritage managers prioritize.
\end{abstract}

Keywords: Geological and palaeontological heritage, heritage assessment, heritage management. 


\section{INTRODUCCIÓN}

El patrimonio geológico y paleontológico se halla en permanente situación de riesgo por diversos motivos que se encuentran interrelacionados de forma compleja. Por ejemplo, la presión urbanística y el desarrollo que sufren las zonas litorales del Mediterráneo español generalmente constituyen una seria amenaza para el mismo. Los actos vandálicos, la práctica del expolio y el deterioro de los enclaves naturales por la excesiva afluencia de visitantes o la mala gestión de las visitas son otros ejemplos de graves amenazas.

Las localidades de interés geológico y paleontológico constituyen un recurso patrimonial no renovable, y la alteración de su estado natural puede significar la pérdida definitiva de información científica. Además, una adecuada gestión patrimonial puede ser altamente rentable desde muchos puntos de vista (científicos, sociales, culturales, pedagógicos, turísticos, políticos).

En este contexto, la necesidad de conservar el patrimonio geológico y paleontológico suele concitar unanimidad. Otro asunto es establecer lo que debe ser conservado y cómo debe hacerse. Ofrecer este conocimiento, proponiendo prioridades para la gestión basadas en herramientas como la valoración patrimonial, resulta esencial para las entidades encargadas de la gestión.

Los inventarios son una forma muy utilizada para documentar los bienes muebles e inmuebles de interés patrimonial de una determinada zona. Sin embargo, el mero hecho de aparecer en un inventario de cualquier tipo no suele constituir una garantía de protección. Así, no es extraño que localidades inventariadas por las administraciones competentes en patrimonio se encuentren alteradas en grado diverso o incluso hayan sido irreversiblemente dañadas.

Es por ello que las administraciones responsables del patrimonio necesitan disponer de algo más que una descripción científica o técnica de los bienes cuya gestión les ha sido encomendada. Necesitan una valoración comparativa de los mismos con el fin de establecer prioridades para su gestión. Ineludiblemente, la valoración incluye aspectos que no siempre pueden ser cuantificados numéricamente, por lo que debemos asumir que siempre existirá una determinada carga de subjetividad.

Debido a la creciente necesidad de gestionar el patrimonio natural, desde hace algunos años se han desarrollado diferentes metodologías de inventario, valoración y gestión del mismo, tanto geológico como paleontológico, y se han llevado a cabo numerosas acciones en el ámbito de la gestión patrimonial (para una detallada relación bibliográfica, véase Fierro-Bandera, 2015; Sánchez-Ferris, 2015).

Conocedores del avance en el conocimiento y la gestión del patrimonio geológico y paleontológico que se ha realizado en España en los últimos años, exponemos aquí la estrategia que desde hace más de una década desarrolla el Museo Paleontológico de Elche (MUPE), con el objetivo de dar a conocer y exponer de forma argumentada dicha estrategia de gestión.

\section{FOPALI: FÓSILES Y PATRIMONIO DE ALICANTE. DE PROYECTO A ESTRATEGIA}

Desde el año 1998 la Comunidad Valenciana cuenta con una legislación que regula directamente el patrimonio paleontológico y geológico regional (Ley 5/2007, de 9 de febrero, de la Generalitat, de modificación de la Ley 4/1998, de 11 de junio, del Patrimonio Cultural Valenciano). A pesar de este marco normativo y de otras medidas legislativas relacionadas (por ejemplo, SánchezFerris, 2018; Santos-Cubedo, 2018), se carece de una estrategia de gestión y de un reglamento específico que desarrolle la norma.

El trabajo que se describe en este artículo ha sido realizado como parte de las actividades del MUPE, entre cuyas prioridades se encuentra la conservación del patrimonio geológico y paleontológico, particularmente el de su entorno geográfico más próximo. Desde el inicio de sus actividades en 2004 (y anteriormente como Grupo Cultural Paleontológico de Elche desde 1982), se han llevado a cabo numerosas intervenciones con tal objetivo: inventarios de yacimientos y colecciones, prospecciones y excavaciones, exposiciones temporales y permanentes, colaboraciones con instituciones públicas y privadas, etc. (Marín-Ferrer, 2008).

En 2006, ante la necesidad de coordinar todas estas actividades, dotarlas de un contenido teórico y desarrollar protocolos de actuación eficaces, se diseña FOPALI (Fósiles y Patrimonio de Alicante), un proyecto cuyo objetivo era documentar, inventariar, valorar, proteger y divulgar el patrimonio geológico y paleontológico de la provincia de Alicante (Fierro-Bandera, 2008; Sánchez-Ferris, 2008). De esta forma, podía entenderse la participación del MUPE, como museo reconocido por la administración competente, en la gestión del patrimonio geológico y paleontológico.

El esquema de trabajo del Proyecto FOPALI toma como punto de partida la existencia de un patrimonio geológico y paleontológico que se registra en forma de inventario (Fig. 1). Las fuentes utilizadas para obtener la información reflejada en un inventario pueden ser muy variadas (publicaciones científicas, proyectos de investigación, tesis doctorales, archivos de instituciones públicas y privadas, asociaciones de aficionados, prospecciones, etc.). El inventario queda organizado en forma de registros con diferentes campos que permiten recopilar la información de manera ordenada (datos geográficos, datos administrativos, datos bibliográficos y culturales, 


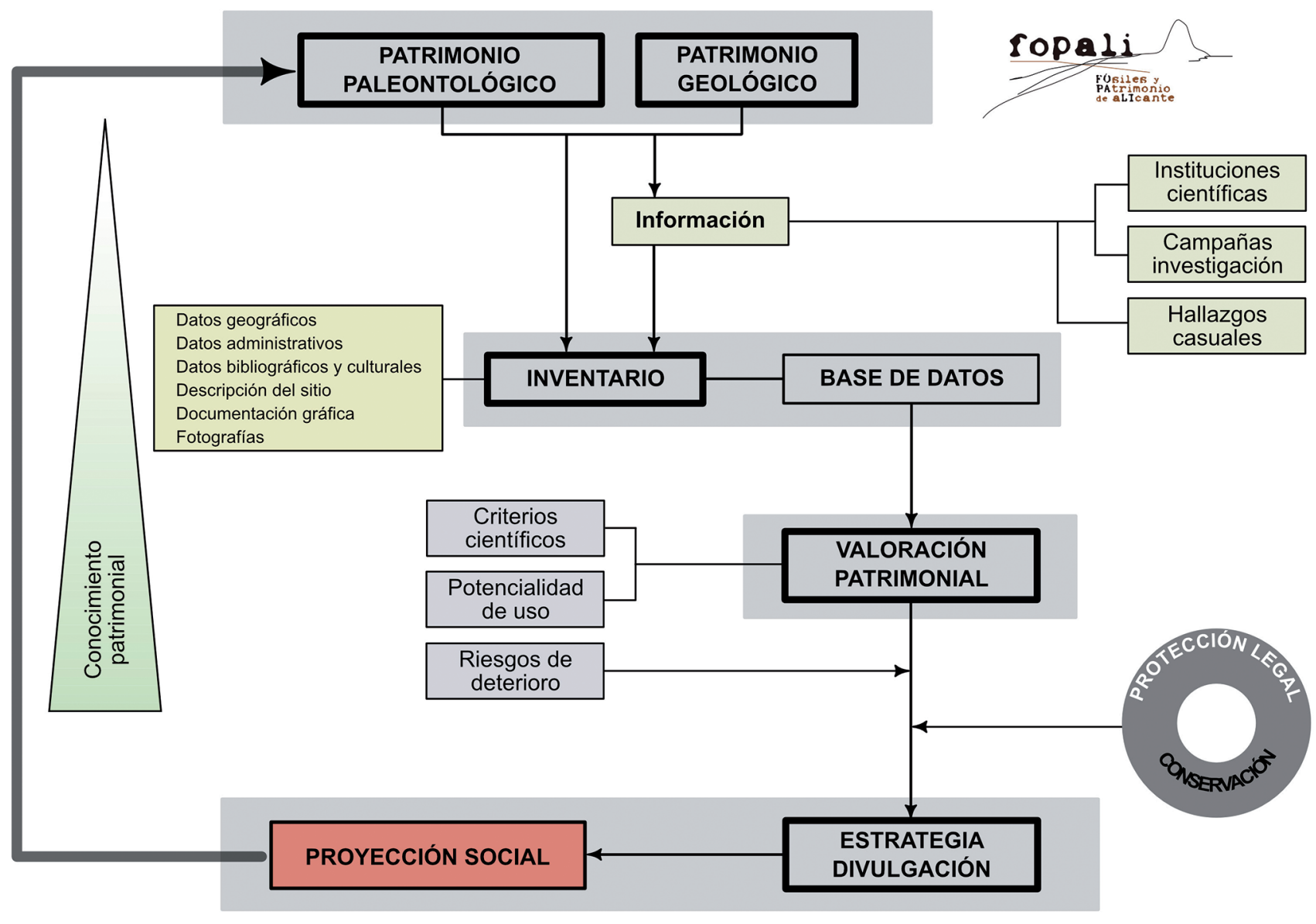

Figura 1. Esquema conceptual de FOPALI junto al logotipo original del proyecto, en el que se contemplan fases de investigación (inventario y valoración), conservación y comunicación del patrimonio geológico y paleontológico.

descripción del yacimiento y documentación gráfica). El siguiente paso lo constituye la valoración patrimonial de los puntos recogidos en el inventario. Para ello se utiliza un conjunto de criterios que permite ordenar los bienes patrimoniales según su importancia. Por último, no debe olvidarse la proyección social como una de las finalidades más importantes de este proyecto, lo que implica el desarrollo de propuestas de gestión y puesta en valor de las localidades inventariadas y valoradas.

A partir del año 2007 el MUPE pasa a depender de la Fundación Cidaris, entidad privada que, desde entonces, se encarga de la gestión del museo. En los Estatutos de la Fundación se recogen los principios básicos que rigen su funcionamiento y que se encuentran claramente asociados al patrimonio, sus valores y su interés social. Este nuevo impulso permite considerar a FOPALI como el proyecto estrella del museo y abre sus puertas, de la mano de la Fundación, a su aplicación en otros territorios gracias a proyectos que van surgiendo en nuevas comunidades autónomas, por ejemplo, el Proyecto ICTIO, (Región de Murcia) (Fierro-Bandera et al., 2007) o en el extranjero, como el Proyecto PALDES (Níger) (Fierro-Bandera et al., 2009).
En el contexto del Proyecto FOPALI, los estudios sobre patrimonio paleontológico poseen entidad propia, complementando y siendo complementados por los referentes al patrimonio geológico. Del mismo modo que en la investigación científica básica se tiende a abordar problemas complejos mediante la participación de equipos multidisciplinares, parece razonable que la gestión del patrimonio global de un territorio siga este mismo camino. En este sentido, el trabajo conjunto de paleontólogos, geólogos, biólogos, arqueólogos, historiadores, geógrafos y ambientólogos ha constituido la mejor estrategia.

A lo largo de los últimos años, el MUPE y la Fundación Cidaris han llevado a cabo diversas actuaciones en el marco del Proyecto FOPALI que han sido muy útiles para la calibración y puesta a punto de la metodología de inventario, valoración y gestión (entre otros, FierroBandera et al., 2007; Fierro-Bandera \& Sánchez-Ferris, 2007; Fierro-Bandera \& Marín-Ferrer, 2008; FierroBandera, 2008, 2010, 2015; Sánchez-Ferris et al., 2009, 2010, 2014; Sánchez-Ferris \& Fierro-Bandera, 2009; Sánchez-Ferris, 2015; Corbí et al., 2017). 
Así, actualmente, FOPALI propone una estrategia que contempla programas de investigación, conservación y comunicación del patrimonio geológico y paleontológico. Este enfoque de gestión permite entender y atender al patrimonio en esta triple vertiente, evitando el desarrollo de actividades aisladas carentes de sentido.

\section{FOPALI: UN MODELO DE GESTIÓN}

Como hemos indicado, FOPALI toma como premisa que la gestión del patrimonio se basa en la investigación, la conservación y la comunicación del mismo. En ocasiones se minimiza el trabajo de aquellos profesionales que se dedican al patrimonio pensando que su principal función se relaciona con la conservación. De hecho, aunque esta es una de las facetas más importantes, no puede abordarse si previamente no se realiza una investigación, y todo lo anterior adquiere pleno sentido con una adecuada comunicación social y educativa sobre los valores del patrimonio de un determinado territorio. Más aún si tenemos en cuenta que las intervenciones patrimoniales tienen por objeto bienes públicos y, muchas veces, su financiación corre a cuenta de fondos también públicos.

Así, entendemos que las actividades de conservación y comunicación no pueden (o no deben) abordarse sin considerar la primera: la investigación del patrimonio. Por otro lado, algunos geólogos y paleontólogos que se dedican a la investigación lo hacen trabajando "con patrimonio" pero sin que esto necesariamente signifique que se encuentran trabajando "en patrimonio". De este modo, nuestra consideración del patrimonio en FOPALI establece que la investigación del mismo se basa en el inventario y en la valoración patrimonial de elementos muebles e inmuebles, cuestiones claramente diferenciadas de la investigación básica relacionada con el conocimiento taxonómico, tafonómico, estratigráfico, sedimentológico, etc., de un determinado enclave o bien.

Así, el primer paso en el estudio del patrimonio es la catalogación de los puntos y áreas de interés, ya que para gestionar un recurso es imprescindible identificarlo y conocerlo, y así poder abordar posteriormente su valoración patrimonial (Carcavilla-Urquí et al., 2007). Contar con un inventario adecuado y con criterios para la demarcación de zonas con más o menos posibilidades de hallazgos previene la improvisación en caso de hallazgos casuales o debidos, por ejemplo, a obras que supongan una remoción de terrenos, con lo que disminuye la frecuencia de las llamadas "actuaciones de urgencia".

La catalogación toma cuerpo en forma de inventario de puntos de interés. En muchos casos, tales inventarios se limitan a un listado de lugares relevantes, aunque lo ideal es que un estudio patrimonial vaya más allá de la descripción, e incorpore un análisis de la información. La realización de un inventario debe poseer unos objetivos e incluir los datos recopilados y una valoración (absoluta o relativa) de los lugares de interés.

En el caso de la paleontología es posible hallar restos fósiles directos o indirectos en casi cualquier contexto sedimentario. Es por ello que necesitamos establecer ciertos criterios básicos para seleccionar aquellos yacimientos, afloramientos, restos, etc., que realmente sean importantes desde un punto de vista patrimonial. Coincidimos con Babin (1992) y Alcalá \& Morales (1994) en que se conocen numerosos yacimientos paleontológicos (y lugares de interés geológico, añadimos nosotros) pero no todos tienen la misma importancia, y como no se pueden proteger todos y también carece esto de sentido, es necesario priorizar. Para Alcalá \& Morales (1994) y Morales (1996), es preferible disponer de un menor número de localidades bien protegidas $\mathrm{y}$ gestionadas antes que una cantidad enorme que haga imposible la conservación de lo que es realmente excepcional e irremplazable.

Por lo que respecta a la geología, nos encontramos con la dificultad añadida de que las formaciones geológicas constituyen la base de cualquier paisaje. De nuevo, necesitaremos de criterios de selección que nos permitan diferenciar lo común de lo excepcional. Además, la excepcionalidad de un elemento geológico o paleontológico muchas veces es una cuestión de escala; lo que es escaso a nivel nacional puede ser muy común a nivel local o regional.

En el modelo de Carcavilla-Urquí et al. (2007) se considera que la valoración patrimonial debe basarse en tres premisas: que no todo elemento paleontológico o geológico posee valor patrimonial, que aquellos que lo poseen no siempre resultan igualmente interesantes o importantes, y que es posible definir unos parámetros o criterios que nos permitan calcular el valor patrimonial. Por lo que se refiere a la primera premisa, es claramente excluyente según la definición de Patrimonio con la que trabaja dicho modelo. Los elementos que carezcan de valor no son patrimonio. Situación que además puede cambiar con el tiempo: lo que no es patrimonio ahora puede serlo en el futuro y a la inversa.

En el modelo de valoración de FOPALI todos los elementos paleontológicos (muebles e inmuebles) son considerados patrimonio (Fig. 2). Esto es así porque el concepto de patrimonio se encuentra desligado del concepto de valor, siendo la gestión del patrimonio la que sí debe vincularse al valor del mismo. Así, el resultado de la valoración patrimonial simplemente nos tiene que indicar qué podemos hacer con determinados enclaves y cuál es la prioridad en su gestión cuando comparamos un conjunto de ellos. 


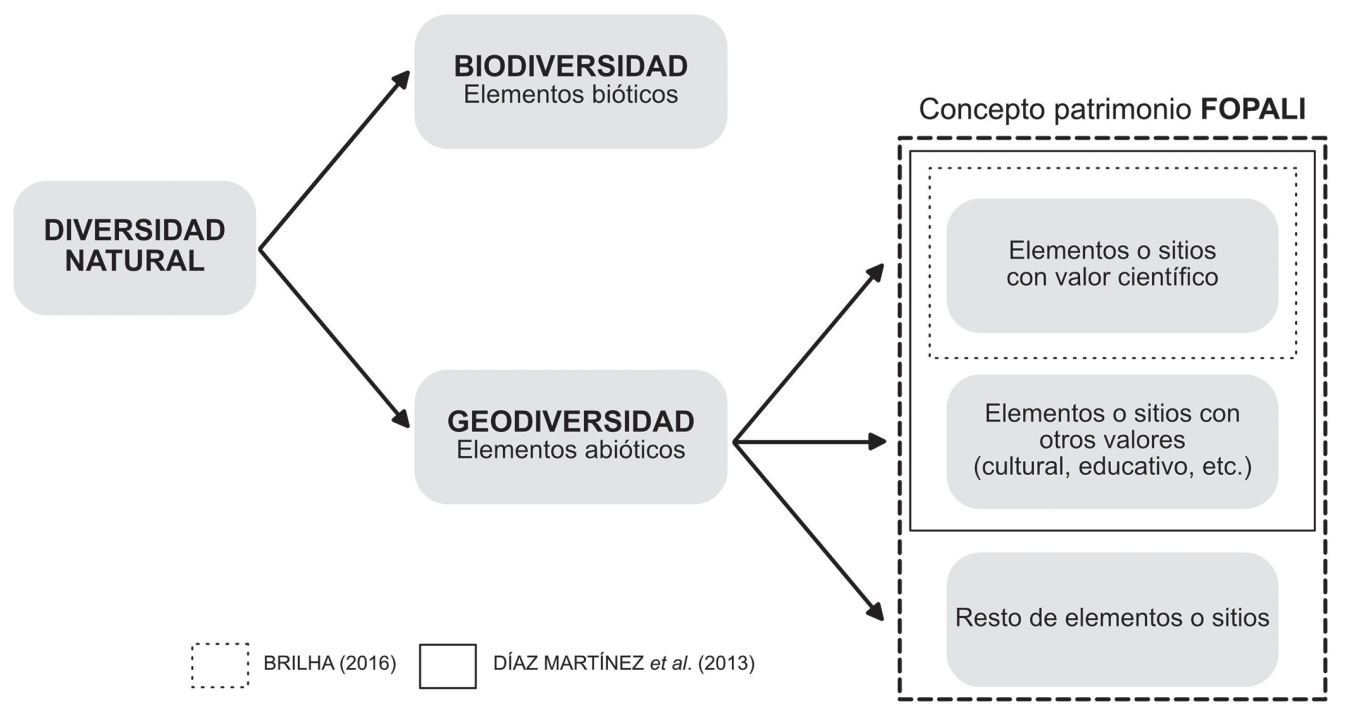

Figura. 2. Esquema simplificado del ámbito de aplicación actual del concepto de patrimonio geológico (modificado de Brilha, 2016). Para Díaz-Martínez et al. (2013) el patrimonio está constituido por elementos con valor científico, cultural, educativo (cuadro de trazo continuo). Para Brilha (2016), solo los elementos con valor científico pertenecen al patrimonio geológico (cuadro de trazo punteado). En el modelo de FOPALI el patrimonio engloba los elementos anteriores junto al resto de elementos de la geodiversidad (línea discontinua).

Sobre estas definiciones, que son elementos básicos, se articulan diferentes modelos de valoración del patrimonio. $\mathrm{Si}$ las definiciones son diferentes, entonces los modelos deberían ser diferentes. Criado-Boado (1996) señala que un error común en los estudios de patrimonio es confundir opinión con interpretación y de ahí pasar a una valoración o evaluación. La valoración se diferencia de la opinión en que constituye un estudio racional de supuestos alternativos basado en el diagnóstico de toda la información disponible. Para este autor el proceso valorativo comienza recogiendo "datos históricos" como materia prima y se reintroducen en un contexto de uso actual dentro del cual adoptan valores nuevos: es lo que se denomina cadena interpretativa (para más información, véase Moreno-Benítez, 2002).

Asumimos que la presencia de cierta subjetividad en un modelo de valoración es inevitable, tanto por el propio hecho de valorar (acción con una carga subjetiva en sí misma), como por la selección de los criterios de valoración y sus baremos. La subjetividad ha sido analizada principalmente en los estudios del paisaje, en los que se valora la calidad visual y estética del mismo, características que varían dependiendo del espectador y del momento. Consideramos que la subjetividad en la valoración del patrimonio geológico y paleontológico no suele ser tan elevada como en las valoraciones del paisaje, ya que contamos con parámetros intrínsecos que son más objetivos de cuantificar.

En Carcavilla-Urquí et al. (2007) se comentan diferentes sistemas de análisis de la subjetividad aplicados a la valoración, entre ellos, el utilizado en el modelo de FOPALI: la subjetividad compartida. En este sistema, la valoración se somete a discusión hasta que todos los miembros del grupo de trabajo aceptan una decisión común argumentada. El modo de minimizar esta subjetividad en la valoración del patrimonio se realiza mediante la participación de diferentes especialistas, ya que aportan interpretaciones diferentes de un mismo criterio y diferentes tipos de valoraciones. El mero hecho de someter a discusión las diferentes opiniones ya supone una importante reducción de la subjetividad.

Otra característica de FOPALI es que utiliza un conjunto de criterios de valoración seleccionados por su utilidad como descriptores de los aspectos que definen una localidad y por su correspondencia formal con variables independientes. Sólo así podemos estar seguros de no valorar alguna característica más de una vez, lo que supondría una sobreestimación del resultado final. Como seguidamente expondremos, esta es una de las razones por las que no hemos considerado algunos criterios de valoración utilizados por otros autores o hemos fusionado algunos utilizados previamente por separado.

Además, se ha tenido en cuenta que los criterios seleccionados puedan servir para valorar tanto el patrimonio geológico como el paleontológico. Esto convierte a FOPALI en un modelo ampliamente utilizable para cualquier tipo de afloramiento geológico, independientemente de su localización o características. 


\section{CRITERIOS PARA LA VALORACIÓN PATRIMONIAL EN EL MODELO FOPALI}

Varios autores han planteado análisis detallados con objeto de determinar cuáles deben ser los criterios usados y su baremación para la valoración del patrimonio paleontológico o geológico. Entre ellos pueden destacarse los trabajos realizados por García-Cortés et al. (1992, 2014), Alcalá \& Morales (1994), Castillo-Martín (1996), Cendrero (1996a, 1996b), Elizaga \& Palacio (1996), Morales (1996), Morales et al. (1999, 2002), RomeroSánchez \& Iniesta-Sanmartín (1999), Castillo et al. (2000, 2001), Gómez \& Morales (2000), Palacio (2000), Alcalá (2002), Braga \& Villalobos (2002), Luque \& Alcalá (2002), Pesquero et al. (2002), Mancheño et al. (2003), Cobos (2004), Meléndez et al. (2004), Villalobos et al. (2004), Bruschi \& Cendrero (2005), Carcavilla-Urquí (2009), Carcavilla-Urquí et al. (2007), Junta de Andalucía (2008), Fuertes-Gutiérrez et al. (2013), García-Cortés et al. (2013), Mediavilla et al. (2013), Rendón et al. (2013), Vegas et al. (2013), Becerra-Ramírez et al. (2015), FierroBandera (2015) y Sánchez-Ferris (2015). A partir de estos trabajos y nuestra propia experiencia, para el modelo de FOPALI hemos seleccionado ciertos criterios ya existentes, descartado o combinado otros, y añadido algunos nuevos.

En la inmensa mayoría de los modelos de valoración propuestos, los criterios se organizan en grupos atendiendo a diferentes características. Todos ellos coinciden en utilizar un grupo de criterios para valorar el interés científico, aunque utilizan diferentes expresiones ("valor intrínseco", "criterios científicos", "valor científico", "calidad intrínseca", "índice de patrimonio científico"). Incluso algunos autores otorgan una gran preponderancia a los criterios científicos; por ejemplo, para Balanyá et al. (2006) serían, no ya los principales, sino los únicos válidos para una descripción rigurosa.

Otro grupo de criterios es el relacionado con el aprovechamiento social del patrimonio, para el que la diferencia es mayor entre autores. Algunos incluyen aquí todos los criterios que tienen que ver con aspectos culturales, sociales, económicos, turísticos y didácticos ("potencialidad de uso", "valor sociocultural y económico", "índice de uso potencial", "valor de uso"). Sin embargo, otros investigadores separan este tipo de criterios en dos grupos, diferenciando entre criterios socioculturales y socioeconómicos o valor didáctico y valor turístico/ recreativo.

El último grupo engloba los criterios relacionados con el riesgo de deterioro, la necesidad de protección, amenazas para la conservación, vulnerabilidad o susceptibilidad de degradación. En algunas publicaciones se considera que este tipo de criterios no forma parte de la valoración patrimonial sensu stricto, sino de cómo el valor de una localidad puede cambiar al ser alterada por ciertas circunstancias; de ahí que no se utilicen criterios de este tipo en su valoración para un momento dado.

En el modelo de FOPALI hemos diferenciado también tres grandes grupos:

1) Criterios científicos. En este grupo se valoran aquellos aspectos de la localidad (bien inmueble) y de sus elementos geológicos o paleontológicos (bienes muebles) directamente relacionados con la importancia científica.

2) Criterios de potencialidad de uso. Aquí se consideran todos los criterios que permiten describir el interés social de la localidad. A diferencia de otros modelos de valoración, se ha considerado oportuno reunir en este grupo los criterios referidos tanto a aspectos socioculturales como socioeconómicos.

3) Criterios de riesgos de deterioro. Este último grupo engloba todos aquellos criterios (tanto los de carácter natural como los de origen antrópico) que valoran los riesgos para la conservación del yacimiento o afloramiento.

En cuanto a los criterios que componen cada grupo, existen diferencias entre los diferentes modelos propuestos en la bibliografía, con una gran heterogeneidad en la selección de los mismos, así como en su número y en el grupo específico en el que distintos autores los encuadran (para más información, véase Sánchez-Ferris, 2015).

Una primera cuestión sería plantear cuántos criterios son realmente necesarios para determinar el valor patrimonial de una localidad. Se trata de una cuestión análoga a la que se plantean los ecólogos cuando quieren determinar el área mínima de muestreo, o a la comentada por Schindel (1980) respecto al muestreo microestratigráfico y los límites de la resolución paleontológica.

El modelo del Proyecto FOPALI se concibió como una herramienta de valoración patrimonial, por lo que los criterios empleados deben responder a este fin, evitando que se produzcan duplicidades o que se valoren aspectos no relevantes. Como comenta Lipps (1981), en ciencia hemos de tener cuidado con los criterios arbitrarios, pues dañan la comprensión del objeto estudiado e incluso el acercamiento intelectual de los científicos que los usan. Además, es aconsejable que el número de criterios empleado no sea excesivo.

Teniendo en cuenta todo lo anterior, para el modelo de FOPALI se han seleccionado un total de veintiocho (28) criterios o parámetros de valoración (algunos compuestos de varios factores), clasificados en los tres grupos previamente citados (Tabla 1). Coincidimos con CarcavillaUrquí et al. (2007) en que utilizar estos tres conjuntos de criterios permite una valoración independiente de las propiedades intrínsecas (criterios científicos), su posible utilización (potencialidad de uso) y los peligros para la conservación (riesgo de deterioro), evitando así mezclar conceptos. 
Tabla 1. Criterios de valoración patrimonial utilizados en el modelo de FOPALI. Se pueden apreciar los tres grandes grupos (científicos, potencialidad de uso y riesgos de deterioro) y los factores en los que se descomponen algunos de los criterios.

\begin{tabular}{|c|c|c|}
\hline Criterios científicos & $\begin{array}{l}\text { 1.- Abundancia de aflorami } \\
\text { 2.- Localidad tipo } \\
\text { 3.- Paleodiversidad / Geodi } \\
\text { 4.- Paleodisparidad } \\
\text { 5.- Estado de conservación } \\
\text { 6.- Estado de conservación } \\
\text { 7.- Interés tafonómico/gené }\end{array}$ & $\begin{array}{l}\text { tos similares } \\
\text { ersidad } \\
\text { pien inmueble) } \\
\text { pienes muebles) } \\
\text { co }\end{array}$ \\
\hline & $\begin{array}{l}\text { 9.- Utilidad para ilustrar pro } \\
\text { 10.- Potencial científico }\end{array}$ & $\begin{array}{l}\text { Bioestratigrafía } \\
\text { Litoestratigrafía } \\
\text { Tectónica } \\
\text { Geomorfología } \\
\text { sos }\end{array}$ \\
\hline $\begin{array}{l}\text { Criterios } \\
\text { potencialidad de } \\
\text { uso }\end{array}$ & $\begin{array}{l}\text { 5.- Proximidad a poblacione } \\
\text { 6.- Número de habitantes en } \\
\text { 7.- Visibilidad } \\
\text { 8.- Accesibilidad }\end{array}$ & $\begin{array}{l}\text { investigación } \\
\text { Paleontología } \\
\text { Arqueología } \\
\text { Espacios naturales } \\
\text { Geología } \\
\text { Infraestructuras } \\
\text { el entorno }\end{array}$ \\
\hline $\begin{array}{l}\text { Criterios riesgos } \\
\text { de deterioro }\end{array}$ & \multicolumn{2}{|c|}{$\begin{array}{l}\text { 1.- Riesgos por accesibilidad } \\
\text { 2.- Riesgos por visibilidad } \\
\text { 3.- Riesgos debidos a proximidad a poblaciones } \\
\text { 4.- Riesgos debidos al número de habitantes en } \\
\text { el entorno } \\
\qquad \begin{array}{l}\text { Vertederos } \\
\text { Edificaciones } \\
\text { Explotaciones } \\
\text { mineras } \\
\text { Agrícolas y } \\
\text { ganaderos } \\
\text { Infraestructuras }\end{array}\end{array}$} \\
\hline
\end{tabular}

Otro aspecto esencial es la definición del sistema de valoración, es decir, de cómo se va a cuantificar cada criterio, su baremación. Hemos optado por utilizar un sistema de cuantificación mixto. Algunos criterios han sido baremados de forma cualitativa-cuantitativa, en una escala del tipo bajo/medio/alto asociada a valores numéricos $(0$, $1,2,3$, etc.), mientras que en otros criterios se establecen unos rangos de valor (por ejemplo, en la distancia a zonas pobladas o en la facilidad de acceso), pero luego se asocian a una escala numérica de tipo $0,1,2$, etc.

\subsection{Criterios científicos}

Los criterios científicos de valoración patrimonial son de gran importancia de cara a establecer el interés real de un lugar concreto, ya que ofrecen información inherente a la propia localidad. Por ello, en ocasiones, estos criterios se denominan intrínsecos y han sido considerados como fundamentales por numerosos autores.

La selección de los criterios que pueden reflejar mejor el interés científico de una localidad ha sido objeto de discusión entre los especialistas. A partir del análisis de los estudios de valoración patrimonial en diferentes publicaciones, los criterios científicos utilizados en el modelo de FOPALI son los siguientes:

\subsubsection{Abundancia de afloramientos similares}

Este criterio hace referencia a la cantidad de yacimientos o zonas de la misma edad, contenido fósil o características geológicas, respecto a la abundancia global a diferentes escalas.

De esta manera se agrupan varios tipos de criterios: a) "Abundancia/Rareza/Diversidad" y "Edad" de GarcíaCortés et al. (1992) y Bruschi \& Cendrero (2005); b) los de "Naturaleza de los fósiles" y "Edad del yacimiento" de Alcalá \& Morales (1994) y de Castillo et al. (2001); c) los de "Tipo de fósiles" y "Edad del yacimiento" de Morales (1996) y Morales et al. (1999); y, d) los de "Abundancia de yacimientos", "Tipo de yacimiento", "Tipo de fósiles" y "Edad del yacimiento" de Castillo et al. (2000) y Mancheño et al. (2003). Todos estos criterios se consideran representativos de la rareza (excepcionalidad) relativa de la localidad. Si se valoraran por separado nos encontraríamos con la necesidad de decidir si un ammonites tiene mayor o menor valor que un dinosaurio, o si el Cretácico es más importante que el Plioceno y, como ya se ha comentado con anterioridad, la relevancia de un grupo de fósiles, una formación geológica o un afloramiento de una edad geológica cualquiera, es una cuestión de escala geográfica. Para Sánchez de Posada et al. (2006): "Ningún criterio racional autoriza a pensar que los fósiles de mayor tamaño o los restos de los ancestros directos de la humanidad constituyen la parte más importante del patrimonio paleontológico". 
También se han incluido criterios utilizados por otros autores, como: a) "Abundancia/Rareza" de Cendrero (1996a, 1996b) y de De la Hera et al. (2013); b) el de “Tipo de fósiles" de Alcalá (2002), Luque \& Alcalá (2002) y Pesquero et al. (2002); c) el de "Rareza" de CarcavillaUrquí (2009), García-Cortés et al. (2013, 2014), Mediavilla et al. (2013), Vegas et al. (2013); y, d) los de "Diversidad" y "Edad geológica" de Rendón et al. (2013).

Así, la baremación de este criterio se ha establecido en relación a la división administrativa y, por lo tanto, en relación con la jurisdicción de los responsables de la gestión.

\subsubsection{Localidad tipo}

Incluye aquellos yacimientos o zonas en los que se ha definido un taxón o unidad geológica. Babin (1992) destaca la peculiaridad de los estratotipos, cuya protección es recomendada por la Comisión Internacional de Estratigrafía. Diversos autores consideran que se trata de un criterio importante que debe tenerse en cuenta (para una relación detallada, véase Sánchez-Ferris, 2015). Sin embargo, existen discrepancias en el modo de baremarlo. Respecto a la paleontología, se ha considerado que un yacimiento a partir de cuyo registro fósil se ha descrito un taxón de rango superior es más importante que aquel que ha proporcionado fósiles para la descripción de un taxón de rango inferior.

\subsubsection{Paleodiversidad/Geodiversidad}

Los análisis de biodiversidad constituyen una herramienta muy útil a la hora de determinar prioridades para la conservación biológica (para más información, véase Eguiarte et al., 1999; Salinas-Gutiérrez, 2003). La aplicación del concepto de diversidad al registro fósil (paleodiversidad) ha sido tradicionalmente enfocada hacia el estudio de la riqueza taxonómica en los afloramientos y su variación a lo largo del tiempo, aunque, cada vez más, comienzan a tenerse en cuenta los factores filogenéticos y el efecto especie-área (para un análisis de la metodología y referencias bibliográficas, véase, entre otros, Barnosky et al., 2005; Lane et al., 2005).

En el modelo de FOPALI se ha optado por utilizar la riqueza taxonómica como aproximación más sencilla al concepto de paleodiversidad. Así, consideramos que poseen un mayor valor científico aquellos yacimientos en los que se encuentra un mayor número de especies diferentes. Alcalá \& Morales (1994), Morales (1996), Morales et al. (1999), Castillo et al. (2000, 2001), Alcalá (2002), Luque \& Alcalá (2002), Pesquero et al. (2002) y Mancheño et al. (2003) también utilizan este criterio, aunque con diferentes denominaciones ("Diversidad de fósiles", "Número de especies" o "Diversidad de taxones").

Por lo que respecta a la geodiversidad, algunos autores (Nieto-Albert, 2001; Balanyá et al., 2006) consideran que este concepto precisa una revisión, pues si se compara con las distintas acepciones del término "biodiversidad", con el que se ha querido establecer un cierto paralelismo, puede verse que factores como la diversidad de especies, diversidad genética o diversidad de ecosistemas no tienen una fácil traslación e identificación con el registro geológico. Algunos enfoques proponen el término "geovariedad" (Ayala-Carcedo, 2000). CarcavillaUrquí et al. (2007, 2008) ofrecen un detallado análisis de la geodiversidad y aportan numerosas referencias bibliográficas. Como conclusión, estos autores consideran que la geodiversidad constituye la diversidad geológica de un territorio, entendida como la variedad de rasgos geológicos presentes en un lugar, identificados tras considerar su abundancia, frecuencia y distribución, y que estos rasgos ilustran la evolución geológica del lugar, por lo que constituiría una propiedad intrínseca. Los mismos autores comentan diferentes modos de evaluar la geodiversidad, desde considerar el número de elementos geológicos diferentes hasta aplicar técnicas de análisis de paisaje. Otras definiciones y análisis similares pueden encontrarse en Braga \& Villalobos (2002) y Junta de Andalucía (2008).

En el modelo de valoración que presentamos se ha considerado la geodiversidad como un criterio más entre los que definen el valor científico de una localidad. Entendemos por geodiversidad la variedad de elementos geológicos y estructuras presentes en la localidad estudiada (rocas, minerales, suelos, formas de relieve, formaciones y unidades geológicas y paisajes). Algunos autores que también utilizan este criterio son García-Cortés et al. (1992, 2013, 2014), Cendrero (1996a, 1996b), Bruschi \& Cendrero (2005), Carcavilla-Urquí (2009), De la Hera et al. (2013), Mediavilla et al. (2013) y Vegas et al. (2013).

\subsubsection{Paleodisparidad}

Entendemos por paleodisparidad las grandes variaciones en la morfología o en los planes corporales de los organismos que dieron origen a los fósiles que se pueden extraer de un determinado yacimiento. En este sentido, un yacimiento puede ser muy diverso, pero poco dispar a nivel de filos. Una alta disparidad supone un mayor valor científico. Este es un nuevo criterio que no se encuentra contemplado en los modelos previos de valoración del patrimonio paleontológico. Para el caso del patrimonio geológico, este criterio se excluye de la valoración final.

\subsubsection{Estado de conservación del patrimonio inmueble}

Este criterio hace referencia a la integridad actual de un yacimiento/zona respecto a su estado original. Algunos 
autores, como Rendón et al. (2013), no incluyen el estado de conservación inmueble como criterio científico, sino dentro del grupo "Índice de amenazas". En el modelo de FOPALI, al igual que para García-Cortés et al. (1992, 2013, 2014), Cendrero (1996b), Bruschi \& Cendrero (2005), Carcavilla-Urquí (2009), Mediavilla et al. (2013) y Vegas et al. (2013), se ha considerado como un criterio de valor intrínseco.

\subsubsection{Estado de conservación del patrimonio mueble}

El estado de preservación de los fósiles es importante para poder estudiar las características anatómicas de los organismos, su filogenia, etc. Así, los sitios con las faunas mejor preservadas tendrán una mayor importancia, criterio también considerado por numerosos autores (Alcalá \& Morales, 1994; Morales, 1996; Castillo et al., 2000, 2001; Alcalá, 2002; Luque \& Alcalá, 2002; Pesquero et al., 2002; Mancheño et al., 2003; Cobos, 2004). Del mismo que para los fósiles de un yacimiento, el estado de conservación de los bienes muebles geológicos que aparecen en un afloramiento influye en el valor científico de la zona. No obstante, no ha sido considerado por otros autores.

\subsubsection{Interés tafonómico/genético}

Este criterio valora el tipo de proceso tafonómico que dio lugar al yacimiento. Procesos tafonómicos inusuales o afloramientos que representen paleoambientes poco alterados se valorarán más que aquellos yacimientos de lo que se infieran procesos tafonómicos más comunes. Otros autores también consideran este criterio (Alcalá \& Morales, 1994; Morales, 1996; Morales et al., 1999; Castillo et al., 2000, 2001; Alcalá, 2002; Luque \& Alcalá, 2002; Pesquero et al., 2002; Mancheño et al., 2003) con expresiones como "Valor tafonómico", "Contextualización tafonómica", "Interés tafonómico" o "Información tafonómica". Del mismo modo, el origen de una formación geológica (interés genético) también se tiene en cuenta.

\subsubsection{Interés geológico}

Alcalá \& Morales (1994), Morales (1996), Morales et al. (1999), Castillo et al. (2000) y Mancheño et al. (2003) definieron este criterio para incluir todo aquel tipo de fenómeno geológico que pudiera aportar cierto interés al punto o zona que se esté valorando. Por su parte, Alcalá (2002), Luque \& Alcalá (2002) y Pesquero et al. (2002) cambian este criterio por el de "Contexto geológico". Todos estos autores, además, incluyen otro criterio al que denominan "Interés/Valor bioestratigráfico". Un caso especial es el de Castillo et al. (2001), quienes proponen criterios como "Vulcanoestratigrafía" o "Insularidad", en una adaptación del modelo de valoración a una zona geográfica muy concreta (las Islas Canarias).

Consideramos que no es necesaria esta multiplicidad de criterios. Para unificar la valoración y simultáneamente cubrir un amplio abanico de posibilidades, dentro del criterio de FOPALI se han considerado cuatro grupos de características geológicas: bioestratigráficas, litoestratigráficas, tectónicas y geomorfológicas. Cada una de ellas se valora por separado, con lo que el resultado final será la media de las cuatro valoraciones aproximadas a la unidad.

\subsubsection{Utilidad del afloramiento como modelo para ilustrar procesos paleobiológicos o geológicos}

Únicamente García-Cortés et al. (1992), Cendrero (1996a, 1996b), Bruschi \& Cendrero (2005) y De la Hera et al. (2013) hacen referencia a este criterio. Así, un yacimiento/ zona en la cual podamos explicar alguno de estos procesos tendría un valor científico añadido. FOPALI tiene en cuenta este criterio ya que por ejemplo existen yacimientos que nos permiten explicar diferentes procesos biológicos como extinción de especies, especiación, asociación entre especies, etc. Un caso puntual es el de Castillo et al. (2000), quienes consideran el "Interés paleoclimatológico" como criterio científico. A nuestro parecer, este tipo de criterio se encontraría incluido en "Utilidad para ilustrar procesos"; en este caso, cómo era y cómo ha cambiado el clima a lo largo de la historia de la Tierra. Por otro lado, Rendón et al. (2013) introducen un criterio al que denominan "Valor científico", y por el cual se refieren a la información que aporta una localidad para la interpretación de la geología regional, lo que podemos considerar una forma de valorar la utilidad para ilustrar procesos geológicos.

\subsubsection{Potencial cientifico}

Escasos autores consideran el potencial científico como un criterio a tener en cuenta. Cuando se utiliza, es en defensa del interés intrínseco de un determinado sitio, tal y como hace Hayward (2009).

En ocasiones, algunos yacimientos pueden ofrecer tras su valoración un escaso interés científico. Esto puede ser debido a su escasa relevancia para la ciencia o al escaso número de investigaciones realizadas hasta la fecha en el mismo (debido a su descubrimiento reciente, a su inaccesibilidad, etc.). Sin embargo, nos parece conveniente valorar de alguna forma el posible interés de un determinado sitio para incrementar la información y el entendimiento de la geología y paleontología en diferentes contextos y escalas.

El potencial científico trata de medir la cantidad de información de interés que un determinado sitio puede potencialmente ofrecernos, independientemente del grado 
de conocimiento o investigación que ya se tenga del mismo. Lógicamente, valorar el potencial de una localidad puede incrementar su valor intrínseco, sin poder asegurar que las expectativas científicas se vean confirmadas en el futuro.

En la Tabla 2 se ofrece el baremo de los criterios científicos descritos. publicaciones sobre una localidad concreta. Sin embargo, no existe consenso acerca de si se trata de una medida del valor intrínseco (criterio científico) o del valor sociocultural (potencialidad de uso). Así, Morales (1996), Castillo et al. $(2000,2001)$ y Mancheño et al. (2003) lo consideran un criterio de tipo sociocultural y lo denominan "Nivel de conocimientos". Sin embargo, es mucho mayor el número de publicaciones que lo consideran un criterio

Tabla 2. Baremo para los criterios científicos del modelo FOPALI.

\begin{tabular}{|c|c|c|c|c|c|}
\hline $\begin{array}{c}\text { CRITERIOS CIENTÍFICOS } \\
\text { FOPALI }\end{array}$ & $\mathbf{0}$ & 1 & 2 & 3 & 4 \\
\hline $\begin{array}{l}\text { Abundancia de afloramientos } \\
\text { similares }\end{array}$ & $\begin{array}{l}\text { Presente en más } \\
\text { de un lugar en el } \\
\text { municipio }\end{array}$ & $\begin{array}{l}\text { Único en el } \\
\text { municipio }\end{array}$ & $\begin{array}{l}\text { Único en la } \\
\text { Comunidad } \\
\text { Autónoma }\end{array}$ & Único en España & Único en el mundo \\
\hline Localidad tipo & No es localidad tipo & & $\begin{array}{l}\text { Nivel específico } \\
\text { / una unidad } \\
\text { geológica }\end{array}$ & & $\begin{array}{l}\text { Nivel genérico / } \\
\text { más de una unidad } \\
\text { geológica }\end{array}$ \\
\hline Paleodiversidad / Geodiversidad & $\begin{array}{l}1-5 \text { spp. / elementos } \\
\text { geológicos }\end{array}$ & $\begin{array}{l}\text { 6-10 spp. / } \\
\text { elementos } \\
\text { geológicos }\end{array}$ & $\begin{array}{l}\text { 11-15 spp. } \\
\text { / elementos } \\
\text { geológicos }\end{array}$ & $\begin{array}{l}\text { 16-20 spp. } \\
\text { / elementos } \\
\text { geológicos }\end{array}$ & $\begin{array}{l}>20 \text { spp. / } \\
\text { elementos } \\
\text { geológicos }\end{array}$ \\
\hline Paleodisparidad & 1 filo & 2 filos & 3 filos & 4 filos & $>4$ filos \\
\hline $\begin{array}{l}\text { Estado de conservación } \\
\text { inmueble }\end{array}$ & $\begin{array}{l}\text { Fuertemente } \\
\text { deteriorado }\end{array}$ & $\begin{array}{l}\text { Características } \\
\text { claves deterioradas }\end{array}$ & $\begin{array}{l}\text { Afectado pero } \\
\text { se aprecian } \\
\text { características claves }\end{array}$ & Algún deterioro & $\begin{array}{l}\text { Perfectamente } \\
\text { conservado }\end{array}$ \\
\hline Estado de conservación mueble & Muy malo & Malo & Regular & Bueno & Muy bueno \\
\hline Interés tafonómico / genético & Muy bajo & Bajo & Medio & Alto & Muy alto \\
\hline Interés geológico & \multicolumn{5}{|c|}{ Media aproximada a la unidad } \\
\hline Bioestratigrafía & Muy bajo & Bajo & Medio & Alto & Muy alto \\
\hline Litoestratigrafía & Muy bajo & Bajo & Medio & Alto & Muy alto \\
\hline Tectónica & Muy bajo & Bajo & Medio & Alto & Muy alto \\
\hline Geomorfología & Muy bajo & Bajo & Medio & Alto & Muy alto \\
\hline Utilidad para ilustrar procesos & Muy bajo & Bajo & Medio & Alto & Muy alto \\
\hline Potencial científico & Muy bajo & Bajo & Medio & Alto & Muy alto \\
\hline
\end{tabular}

\subsection{Criterios de potencialidad de uso}

Los autores que han trabajado sobre modelos de valoración patrimonial suelen contemplar estos criterios como socioculturales, socioeconómicos o extrínsecos, porque su valor está relacionado con la posibilidad de obtener un beneficio y, por lo tanto, de ser considerados como recursos. En el modelo de FOPALI se han considerado los siguientes criterios:

\subsubsection{Grado de conocimiento o investigación}

Este criterio es uno de los más utilizados en los estudios patrimoniales, y hace referencia al número y tipo de de valor intrínseco (García Cortés et al., 1992, 2013, 2014; Alcalá \& Morales, 1994; Cendrero, 1996a, 1996b; Alcalá, 2002; Braga \& Villalobos, 2002; Luque \& Alcalá, 2002; Pesquero et al., 2002; Cobos, 2004; Villalobos et al., 2004; Bruschi \& Cendrero, 2005; Junta de Andalucía, 2008; Carcavilla-Urquí, 2009; De la Hera et al., 2013; Mediavilla et al., 2013; Vegas et al., 2013). Incluso Rendón et al. (2013) creen que se trataría de un criterio que permite valorar el grado de amenaza para la conservación de una localidad. Además, la denominación del criterio varía mucho entre los diferentes autores: "Grado de conocimiento o investigación", "Nivel de conocimientos", "Índice bibliométrico", "Grado de conocimiento científico" o "Conocimiento científico". 
La cuestión que deberíamos aclarar es si el hecho de que dispongamos de un mayor conocimiento de una localidad implica un aumento del valor científico de la misma. En nuestra opinión, el valor científico viene dado por la naturaleza de los bienes muebles e inmuebles que constituyen el patrimonio. Los bienes geológicos y paleontológicos tienen un origen natural, por lo que su valor intrínseco estaría relacionado con aspectos naturales. La investigación científica y, como consecuencia, el aumento de conocimiento (medible por ejemplo en número de publicaciones referidas a una localidad concreta), constituyen fenómenos de la esfera social, productos de la actividad humana. Así, el grado de conocimiento sería un parámetro de potencialidad de uso, pues sí que es cierto que cuanto más sepamos de una localidad, mayor aprovechamiento social podremos obtener de ella.

\subsubsection{Valor histórico}

Alcalá \& Morales (1994), Cendrero (1996a), Morales (1996), Morales et al. (1999), Castillo et al. (2000, 2001), Alcalá (2002), Luque \& Alcalá (2002), Pesquero et al. (2002), Mancheño et al. (2003) y De la Hera et al. (2013) utilizan este criterio sociocultural (con denominaciones como "Valor histórico", "Interés o significado en la historia de la investigación geológica" o "Historia de la ciencia") haciendo referencia a los yacimientos que forman parte de la historia de la Paleontología. En el modelo de FOPALI, no es nuestra tarea definir la importancia de la aportación a la historia de la Paleontología o la Geología, pero sí podemos valorar la referencia más antigua del yacimiento/zona. Así, cuanto más antigua sea, mayor será el valor. Para nuestra baremación, hemos tomado la utilizada por Alcalá (2002).

\subsubsection{Interés didáctico}

Cualquier yacimiento, sitio de interés o zona, por sí mismos, pueden utilizarse como herramienta didáctica, pues siempre ofrecen alguna información sobre los fósiles o los niveles que los contienen. Alcalá \& Morales (1994) hacen referencia con este criterio a la potencialidad de los yacimientos para su utilización en prácticas docentes de cualquier tipo. Además, este criterio también ha sido considerado por Morales (1996), Morales et al. (1999), Castillo et al. (2000, 2001), Alcalá (2002), Braga \& Villalobos (2002), Luque \& Alcalá (2002), Pesquero et al. (2002), Mancheño et al. (2003), Villalobos et al. (2004), Junta de Andalucía (2008), Carcavilla-Urquí (2009), García-Cortés et al. (2013, 2014), Mediavilla et al. (2013), Vegas et al. (2013) y Rendón et al. (2013). Estos autores le han dado diferentes nombres: "Interés didáctico", "Valor didáctico", "Interés pedagógico", "Contenido didáctico", "Didáctico", "Potencial educativo" o "Uso didáctico".

Su baremación se ha basado en las características del afloramiento que permitirían su aprovechamiento didáctico.

\subsubsection{Valor complementario}

Este criterio valora positivamente aquellos lugares en cuyas cercanías se encuentren otros elementos patrimoniales de interés, como yacimientos arqueológicos, espacios naturales (sean protegidos o no), equipamientos culturales o infraestructuras, otros yacimientos/zonas paleontológicos, paisajes singulares, sus vías de comunicación, así como una geología excepcional.

Ha sido utilizado por varios autores, aunque no siempre como indicativo de la potencialidad de uso. Por ejemplo, García-Cortés et al. (1992), Cendrero (1996b), Castillo et al. (2001) y Bruschi \& Cendrero (2005) consideran que se trata de un criterio científico, y utilizan expresiones como "Asociación con otros elementos culturales", "Asociación con otros elementos naturales", "Asociación con restos arqueológicos", "Asociación con patrimonio histórico, arqueológico o artístico" o "Asociación con otro patrimonio natural".

En otros modelos se le considera un criterio de la potencialidad de uso (Alcalá, 2002; Braga \& Villalobos, 2002; Luque \& Alcalá, 2002; Pesquero et al., 2002; Mancheño et al., 2003; Cobos, 2004; Villalobos et al., 2004; Junta de Andalucía, 2008; Carcavilla-Urquí, 2009; GarcíaCortés et al., 2013, 2014; Mediavilla et al., 2013; Rendón et al., 2013; Vegas et al., 2013), con denominaciones como "Valor complementario", "Patrimonio natural", "Infraestructura logística", "Posición en la RENPA (Red de Espacios Naturales Protegidos de Andalucía)", "Asociación con otros recursos ecoculturales", "Asociación con otros patrimonios", "Otros recursos naturales", "Otros recursos culturales", "Asociación con elementos ecoculturales", "Relación con otros elementos ambientales" o "Asociación con otros elementos del patrimonio natural, histórico o etnológico (tradiciones)". Además, en varias ocasiones se utiliza más de uno de estos criterios en un único modelo, separando, por ejemplo, recursos naturales de recursos culturales. Algunos autores incluso los colocan en grupos de valoración diferentes, por ejemplo, Alcalá \& Morales (1994), Morales (1996), Morales et al. (1999) y Castillo et al. (2000), quienes consideran criterio científico la "Asociación con restos arqueológicos", y criterio sociocultural el "Valor complementario".

En el modelo de FOPALI hemos unificado estos criterios teniendo en cuenta que lo que se valora es la relación con otro elemento, no el tipo de elemento. Así, su valor depende del número de estos elementos.

\subsubsection{Proximidad a poblaciones}

Este criterio, como otros que veremos a continuación, posee una componente positiva y otra negativa. Por un lado, la cercanía de un lugar de interés geológico o paleontológico a núcleos poblados favorece su aprovechamiento social, pues facilita el acceso y la logística necesaria cuando se 
organizan visitas o para su acondicionamiento turístico, por ejemplo. Esta sería la componente positiva. Pero desgraciadamente, debido al expolio y a las prácticas poco respetuosas con el patrimonio natural, el hecho de que una localidad se encuentre relativamente alejada de las poblaciones en ocasiones es una forma de asegurar su conservación. Así, la proximidad a poblaciones constituye también un factor de riesgo que analizaremos más adelante.

En este grupo de criterios de potencialidad de uso consideramos la parte positiva de esa proximidad a poblaciones, un criterio utilizado por autores como GarcíaCortés et al. (1992, 2013, 2014), Alcalá \& Morales (1994), Cendrero (1996a, 1996b), Morales (1996), Morales et al. (1999), Castillo et al. (2000, 2001), Mancheño et al. (2003), Bruschi \& Cendrero (2005), Carcavilla-Urquí (2009), De la Hera et al. (2013), Mediavilla et al. (2013) y Vegas et al. (2013), con la denominación de "Proximidad a poblaciones", "Situación geográfica", "Proximidad a centros de servicio" o "Cercanía a zonas recreativas". Estos dos últimos criterios han sido incluidos aquí porque el aspecto esencial que valoran es la distancia.

\subsubsection{Número de habitantes en el entorno}

Como con el criterio anterior, aquí se ha considerado únicamente el efecto positivo. Un yacimiento próximo a una población mayor es más probable que sea visitado por sus habitantes. En la bibliografía ha sido utilizado por García-Cortés et al. (1992, 2013, 2014), Cendrero (1996a, 1996b), Carcavilla-Urquí (2009), De la Hera et al. (2013), Mediavilla et al. (2013) y Vegas et al. (2013), como "Número de habitantes en el entorno" o "Densidad de población". Para la baremación de FOPALI utilizamos la de Cendrero (1996a, 1996b), referida al número de habitantes dentro de un radio de $25 \mathrm{~km}$.

\subsubsection{Visibilidad}

A la hora de valorar la potencialidad de uso de una localidad es importante tener en cuenta si los elementos que la componen se pueden observar con facilidad. A esta cualidad la hemos denominado "visibilidad" (no confundir con la propiedad del mismo nombre utilizada en los estudios de ordenación del territorio y que hace referencia al potencial de visitas). Como en los casos anteriores, la dualidad de este criterio hace que sea tanto una ventaja en el uso como un riesgo. Considerando el efecto positivo de la visibilidad, cuanto más visible sea un yacimiento los visitantes tendrán mayor facilidad de acceso a la información.

Este criterio también lo contemplan García-Cortés et al. (1992, 2013), Cendrero (1996a, 1996b), Braga \& Villalobos (2002), Villalobos et al. (2004), Bruschi \& Cendrero (2005), Junta de Andalucía (2008), Carcavilla-
Urquí (2009), De la Hera et al. (2013), Mediavilla et al. (2013) y Vegas et al. (2013), con el nombre de "Condiciones de observación".

\subsubsection{Accesibilidad}

El concepto de accesibilidad también es utilizado en los análisis de ordenación del territorio para referirse al tiempo necesario para el acceso a la zona estudiada. En los estudios patrimoniales, sin embargo, sirve para valorar la facilidad para acceder a una localidad de interés.

Este criterio ha sido anteriormente utilizado por GarcíaCortés et al. (1992, 2013, 2014), Cendrero (1996a, 1996b), Braga \& Villalobos (2002), Cobos (2004), Villalobos et al. (2004), Bruschi \& Cendrero (2005), Junta de Andalucía (2008), Carcavilla-Urquí (2009), De la Hera et al. (2013), Mediavilla et al. (2013), Rendón et al. (2013, con la expresión “Acceso vehicular) y Vegas et al. (2013).

En la Tabla 3 se ofrece el baremo de los criterios de potencialidad de uso descritos.

\subsection{Criterios relacionados con los riesgos de deterioro}

En el modelo de FOPALI, el concepto de "riesgo" de alguna manera constituye una medida de la urgencia con la que las administraciones competentes deberían actuar para salvaguardar una localidad.

Fuertes-Gutiérrez et al. (2013) consideran acertadamente que en la bibliografía existe una gran diversidad de términos referidos a los riesgos de deterioro (fragilidad, vulnerabilidad, sensibilidad, etc.) y que es necesario llegar a un acuerdo acerca de su significado para evitar que dos términos diferentes se utilicen para referirse al mismo concepto o que el mismo término tenga distinto significado, incluso contrario. Coincidimos con los autores en que es necesario revisar y definir los criterios cuidadosamente para evitar estos problemas. En el modelo de FOPALI se han considerado los siguientes criterios:

\subsubsection{Riesgos por accesibilidad}

Como ya comentamos, este es uno de los baremos duales (positivos para la potencialidad de uso y negativos para el riesgo de deterioro). Una mayor facilidad de acceso aumenta el riesgo de deterioro accidental o intencionado. Este criterio es también utilizado por García-Cortés et al. (1992, 2013, 2014), Cendrero (1996a, 1996b), Alcalá (2002), Braga \& Villalobos (2002), Luque \& Alcalá (2002), Pesquero et al. (2002), Cobos (2004), Villalobos et al. (2004), Junta de Andalucía (2008), Carcavilla-Urquí (2009), De la Hera et al. (2013), Mediavilla et al. (2013) y Vegas et al. (2013). 
Tabla 3. Baremo para los criterios de potencialidad de uso en el modelo FOPALI.

\begin{tabular}{|c|c|c|c|c|c|c|}
\hline $\begin{array}{c}\text { POTENCIALIDAD DE } \\
\text { USO }\end{array}$ & $\mathbf{0}$ & 1 & 2 & 3 & 4 & 5 \\
\hline $\begin{array}{l}\text { Grado de conocimiento o } \\
\text { investigación }\end{array}$ & Inédito & 1-2 publicaciones & 3-5 publicaciones & 6-10 publicaciones & $\begin{array}{l}11-15 \\
\text { publicaciones }\end{array}$ & $>15$ publicaciones \\
\hline Valor histórico & & Después de 1.990 & $1.990-1.936$ & $1.935-1.900$ & s. XIX & s. XVIII o anterior \\
\hline Interés didáctico & & $\begin{array}{l}\text { Fósiles / } \\
\text { elementos } \\
\text { geológicos o } \\
\text { niveles }\end{array}$ & & $\begin{array}{l}\text { Lo anterior y } \\
\text { paleoambientes } \\
\text { / ambientes } \\
\text { sedimentarios o } \\
\text { procesos }\end{array}$ & & Todo lo anterior \\
\hline \multirow{2}{*}{ Valor complementario } & & Un elemento & Dos & Tres & Cuatro & Cinco \\
\hline & \multicolumn{6}{|c|}{ Yacimientos paleontológicos, yacimientos arqueológicos, espacios naturales, geología, infraestructuras } \\
\hline Proximidad a poblaciones & & $>50 \mathrm{~km}$ & $26-50 \mathrm{~km}$ & $11-25 \mathrm{~km}$ & $5-10 \mathrm{~km}$ & $<5 \mathrm{~km}$ \\
\hline $\begin{array}{l}\text { Número de habitantes en el } \\
\text { entorno }\end{array}$ & & $\begin{array}{l}<10.000 \text { en radio } \\
25 \mathrm{~km}\end{array}$ & $10.000-25.000$ & $25.000-50.000$ & $50.000-100.000$ & $>100.000$ \\
\hline Visibilidad & Nula & $\begin{array}{l}\text { Niveles o bienes } \\
\text { muebles }\end{array}$ & & $\begin{array}{l}\text { Niveles y bienes } \\
\text { muebles }\end{array}$ & & $\begin{array}{l}\text { Niveles, bienes } \\
\text { muebles y } \\
\text { señalización }\end{array}$ \\
\hline Accesibilidad & & $\begin{array}{l}\text { Difícil de acceder } \\
\text { a pie }\end{array}$ & $\begin{array}{l}\text { Difícil de acceder } \\
\text { en vehículo }\end{array}$ & $\begin{array}{l}\text { Accesible en todo } \\
\text { terreno }\end{array}$ & $\begin{array}{l}\text { Accesible en } \\
\text { coche }\end{array}$ & $\begin{array}{l}\text { Accesible en } \\
\text { autobús }\end{array}$ \\
\hline
\end{tabular}

\subsubsection{Riesgos por visibilidad}

Anteriormente hemos considerado el componente positivo de la visibilidad; sin embargo, ocurre lo mismo que para la accesibilidad: cuanto más visible sea una localidad, más fácil será de localizar y, por lo tanto, mayor será el riesgo de sufrir un posible deterioro. Este criterio no ha sido aplicado anteriormente en ningún modelo de valoración.

\subsubsection{Proximidad a poblaciones}

Se considera aquí la componente negativa de este criterio. Cuanto más próximo a una población se encuentre un lugar de interés, mayor será el riesgo de ser deteriorado accidental o intencionadamente. Este criterio también ha sido empleado por García-Cortés et al. (1992), Cendrero (1996a, 1996b) y De la Hera et al. (2013). La distancia se ha baremado respecto al radio de proximidad.

\subsubsection{Número de habitantes en el entorno}

García-Cortés et al. (1992, 2013, 2014), Cendrero (1996a, 1996b), Bruschi \& Cendrero (2005), Carcavilla-Urquí (2009), De la Hera et al. (2013), Mediavilla et al. (2013) y Vegas et al. (2013), ya consideran este componente negativo. Este criterio se basa en la hipótesis de que cuanto mayor sea el número de habitantes en el entorno mayor será la probabilidad de deterioro que tendrá ese yacimiento/ zona. El baremo se ha establecido considerando un área de $25 \mathrm{~km}$ de radio en torno al lugar considerado.

\subsubsection{Usos del suelo}

El uso que se haga del terreno de una localidad y de su entorno más próximo puede hacer que peligre su conservación. Para minimizar la posible influencia negativa de algunas actividades, es aconsejable definir un perímetro de protección. Este asunto ha sido abordado frecuentemente por los investigadores de patrimonio mediante la utilización de numerosos criterios (Tabla 4).

Considerando que el nexo común de todos estos criterios es el uso del suelo, hemos decidido crear un único criterio con este nombre, compuesto de una serie de factores que cubran todas las posibilidades. Así, se han considerado diferentes usos del suelo:

1) Vertederos: el riesgo de deterioro es mayor cuando la localidad inventariada se encuentra en las proximidades de un vertedero legal o incontrolado.

2) Edificaciones: el riesgo de deterioro en aquellas localidades o zonas situadas cerca de edificaciones de cualquier tipo es mayor, pues pueden ser afectadas por la urbanización del terreno.

3) Explotación minera: los afloramientos que se encuentran asociados a explotaciones mineras tienen el elevado riesgo de ser destruidos total o parcialmente. En ocasiones, los fósiles sólo se pueden obtener mientras dura la explotación minera y a veces forman concentraciones fácilmente destruibles (Alcalá \& Morales, 1994).

4) Agrícola y ganadero: las localidades situadas en terrenos de explotación agrícola o ganadera sufren un deterioro debido al labrado o pisoteo de los animales 
Tabla 4. Criterios relacionados con el uso del suelo utilizados en la bibliografía.

\begin{tabular}{|c|c|c|}
\hline Criterios utilizados & Tipo de afección & Referencias bibliográficas \\
\hline $\begin{array}{l}\text { "Situación en el planeamiento vigente" } \\
\text { "Relación con la planificación existente" }\end{array}$ & $\begin{array}{l}\text { Uso determinado por los planes de } \\
\text { ordenación territorial }\end{array}$ & $\begin{array}{l}\text { García-Cortés et al. (1992), Cendrero (1996b), Bruschi \& } \\
\text { Cendrero (2005) }\end{array}$ \\
\hline $\begin{array}{l}\text { "Interés para la explotación minera" } \\
\text { "Valor minero" } \\
\text { "Minería/Canteras" } \\
\text { "Explotación minera" } \\
\text { "Interés para la explotación minera/hídrica" }\end{array}$ & Existencia de actividad minera & $\begin{array}{l}\text { García-Cortés et al. (1992, 2013, 2014), Alcalá \& Morales } \\
\text { (1994), Cendrero (1996b), Morales (1996), Morales et al. } \\
\text { (1999), Castillo et al. (2000a, 2001), Alcalá (2002), Luque \& } \\
\text { Alcalá (2002), Meléndez \& Peñalver (2002a), Peñalver (2002), } \\
\text { Pesquero et al. (2002), Mancheño et al. (2003), Meléndez et al. } \\
\text { (2004), Bruschi \& Cendrero (2005), Carcavilla-Urquí (2009), } \\
\text { Mediavilla et al. (2013), Vegas et al. (2013) }\end{array}$ \\
\hline $\begin{array}{l}\text { "Valor de los terrenos" } \\
\text { "Valor urbano" } \\
\text { "Riesgo especulativo" } \\
\text { "Valor urbanístico" } \\
\text { "Urbanización" }\end{array}$ & $\begin{array}{l}\text { Peligro de un excesivo crecimiento } \\
\text { urbanístico }\end{array}$ & $\begin{array}{l}\text { García-Cortés et al. (1992), Alcalá \& Morales (1994), Castillo- } \\
\text { Martín (1996), Cendrero (1996b), Morales (1996), Morales et } \\
\text { al. (1999), Castillo et al. (2001), Meléndez \& Peñalver (2002a), } \\
\text { Peñalver (2002), Meléndez et al. (2004) }\end{array}$ \\
\hline $\begin{array}{l}\text { "Obras públicas" } \\
\text { "Vías de comunicación" } \\
\text { "Proximidad a infraestructuras" }\end{array}$ & $\begin{array}{l}\text { Afección por la construcción o } \\
\text { existencia de infraestructuras }\end{array}$ & $\begin{array}{l}\text { Alcalá \& Morales (1994), Morales (1996), Morales et al. } \\
\text { (1999), Castillo et al. (2001), Alcalá (2002), Luque \& Alcalá } \\
\text { (2002), Meléndez \& Peñalver (2002a), Peñalver (2002), } \\
\text { Pesquero et al. (2002), Meléndez et al. (2004), Gacía-Cortés } \\
\text { et al. (2014) }\end{array}$ \\
\hline "Edificaciones" & $\begin{array}{l}\text { Presencia de construcciones y afección } \\
\text { a la localidad }\end{array}$ & Alcalá (2002), Luque \& Alcalá (2002), Pesquero et al. (2002) \\
\hline "Vertederos" & $\begin{array}{l}\text { Influencia sobre las localidades de } \\
\text { interés }\end{array}$ & $\begin{array}{l}\text { Alcalá (2002), Luque \& Alcalá (2002), Meléndez \& Peñalver } \\
\text { (2002a), Peñalver (2002), Pesquero et al. (2002), Meléndez } \\
\text { et al. (2004) }\end{array}$ \\
\hline
\end{tabular}

sobre el terreno. Este factor no había sido considerado en anteriores modelos.

5) Infraestructuras: se entiende por infraestructuras obras públicas o privadas como canales, embalses, balsas de riego, puertos, carreteras, autovías, vías férreas, trasvases, etc., ya existentes, así como aquellas previstas, que pudieran afectar a los afloramientos inventariados.

Para establecer el valor de este criterio se consideran todos los usos descritos arriba y se tiene en cuenta el valor medio aproximado a la unidad. Dado que el modelo de valoración de FOPALI ha sido diseñado para facilitar la comparación entre lugares de interés, consideramos que tomar como referencia la media, y no el resultado más alto, permitirá valorar situaciones en las que un mismo lugar se encuentre afectado por más de un uso del suelo.

\subsubsection{Grado de afección por el uso del suelo}

Dependiendo del tipo de uso del suelo, las actuaciones pueden tener un grado mayor o menor de afección sobre aquél. En arqueología, algunos autores definen los grados de afección como compatible, moderado, severo y crítico (para una información más detallada, véase Miranda-Ariz et al., 2003). Este criterio es habitualmente utilizado en los estudios de impacto sobre el patrimonio (SánchezFerris, 2004, 2005), pero es la primera vez que se incluye en un modelo de valoración del patrimonio geológico y paleontológico.

\subsubsection{Vulnerabilidad ante el expolio}

Hay localidades en las que la misma intensidad de expolio puede producir más daño que en otras, bien sea por el tamaño del afloramiento, otras circunstancias geológicas, el estado de conservación, etc. Alcalá \& Morales (1994) definen un criterio de "Vulnerabilidad y fragilidad frente al expolio" que depende de las características del afloramiento, por ejemplo, la fragilidad de los fósiles, la cantidad de estos y su concentración, etc. Otros autores como Meléndez \& Peñalver (2002b), Peñalver (2002), Meléndez et al. (2004) y García-Cortés (2015) también consideran este criterio.

\subsubsection{Susceptibilidad ante el expolio}

Es indiscutible que ciertos tipos de elementos naturales son más apreciados para el coleccionismo o la venta que otros, bien por sus características o por su escasez. Así, se dice que estos elementos son más susceptibles ante el expolio. Este concepto ha sido utilizado de forma más o menos directa, por ejemplo, por Alcalá \& Morales (1994), Castillo-Martín (1996), Morales (1996), Castillo et al. (2001), o por los diferentes ponentes de las I Jornadas sobre Patrimonio de la Provincia de Teruel en 1998 (Meléndez \& Peñalver, 2002a), utilizando expresiones como "Riesgo de expolio", "Coleccionismo", "Valor económico", "Comercio" o "Susceptibilidad al expolio". 


\subsubsection{Frecuencia de expolio}

Existen yacimientos/zonas que por sus características son más frecuentemente expoliados que otros, por lo que la información que nos podrían aportar sobre la historia de la vida se puede ver seriamente comprometida. Un yacimiento más frecuentemente visitado por expoliadores tiene un mayor riesgo de desaparecer. Otros autores que también han considerado este criterio son, por ejemplo, Meléndez \& Peñalver (2002b), Peñalver (2002) y Meléndez et al. (2004).

\subsubsection{Riesgos no antrópicos}

Los fenómenos naturales y la vida salvaje pueden ser tan perjudiciales para una localidad de interés como las actividades humanas. Aquí se tienen en cuenta riesgos naturales como riadas, deslizamientos de tierras, lluvias torrenciales, incendios forestales, erosión del suelo (tanto potencial como actual), etc. Por riesgo geológico entendemos cualquier proceso o evento natural geológico, en ocasiones inducido, que pueda generar un daño a los elementos integrantes del patrimonio geológico y paleontológico.

También consideramos en este punto la fauna y la flora del lugar, ya que pueden influir con deterioros físicos o químicos. Así pues, distinguimos cuatro factores en este criterio: fauna, flora, geodinámica externa y geodinámica interna. Para establecer el valor de este criterio se consideran todos los riesgos no antrópicos y se calcula la media aproximada a la unidad. La explicación de por qué se utiliza la media y no el valor más alto es la misma que para el caso del criterio "Usos del suelo".

Algunos de estos aspectos ya se contemplan parcialmente en los criterios de otros autores, como "Riesgo de alteración mecánica" (Castillo-Martín, 1996), "Erosión natural" (Alcalá, 2002; Luque \& Alcalá, 2002; Pesquero el al., 2002) y "Amenazas naturales" (CarcavillaUrquí, 2009; García-Cortés et al., 2013, 2014; Mediavilla et al., 2013; Vegas et al., 2013).

En la Tabla 5 se ofrece el baremo de los criterios de riesgos de deterioro.

Tabla 5. Baremo para los criterios de riesgos de deterioro del modelo FOPALI.

\begin{tabular}{|c|c|c|c|c|c|}
\hline RIESGOS DE DETERIORO & $\mathbf{0}$ & 1 & 2 & 3 & 4 \\
\hline Accesibilidad & $\begin{array}{l}\text { Difícil de acceder } \\
\text { a pie }\end{array}$ & $\begin{array}{l}\text { Difícil de acceder en } \\
\text { vehículo }\end{array}$ & $\begin{array}{l}\text { Accesible en } \\
\text { todoterreno }\end{array}$ & Accesible en coche & Accesible en autobús \\
\hline Riesgos por visibilidad & Nula & Se reconocen niveles & $\begin{array}{l}\text { Se reconocen bienes } \\
\text { muebles }\end{array}$ & $\begin{array}{l}\text { Se reconocen niveles } \\
\text { y bienes muebles }\end{array}$ & $\begin{array}{c}\text { Se reconocen niveles } \\
\text { y bienes muebles y } \\
\text { está señalizado }\end{array}$ \\
\hline Proximidad a poblaciones & $>50 \mathrm{~km}$ & $26-50 \mathrm{~km}$ & $11-25 \mathrm{~km}$ & $5-10 \mathrm{~km}$ & $<5 \mathrm{~km}$ \\
\hline $\begin{array}{l}\text { Número de habitantes en el } \\
\text { entorno }\end{array}$ & $<10000$ en $25 \mathrm{~km}$ & $10000-25000$ & $25000-50000$ & $50000-100000$ & $>100000$ \\
\hline Usos del suelo & \multicolumn{5}{|c|}{ Media aproximada a la unidad } \\
\hline Vertederos & Inexistentes o lejanos & Proyectados & Ocasionales & Obras iniciadas & En funcionamiento \\
\hline Edificaciones & Inexistentes o lejanos & Proyectados & Ocasionales & Obras iniciadas & En funcionamiento \\
\hline Explotación minera & Inexistentes o lejanos & Proyectados & Ocasionales & Obras iniciadas & En funcionamiento \\
\hline Agrícola y ganadero & Inexistentes o lejanos & Proyectados & Ocasionales & Obras iniciadas & En funcionamiento \\
\hline Infraestructuras & Inexistentes o lejanos & Proyectados & Ocasionales & Obras iniciadas & En funcionamiento \\
\hline $\begin{array}{l}\text { Grado de afección por el uso } \\
\text { del suelo }\end{array}$ & & Compatible & Moderado & Severo & Crítico \\
\hline Vulnerabilidad ante el expolio & Nula o muy baja & Baja & Media & Alta & Muy alta \\
\hline Susceptibilidad ante el expolio & Nula o muy baja & Baja & Media & Alta & Muy alta \\
\hline Frecuencia de expolio & Nula o desconocida & & Ocasional & & Sistemática \\
\hline Riesgos no antrópicos & \multicolumn{5}{|c|}{ Media aproximada a la unidad } \\
\hline Fauna & Muy bajo & Bajo & Medio & Alto & Muy alto \\
\hline Flora & Muy bajo & Bajo & Medio & Alto & Muy alto \\
\hline Geodinámica externa & Muy bajo & Bajo & Medio & Alto & Muy alto \\
\hline Geodinámica interna & Muy bajo & Bajo & Medio & Alto & Muy alto \\
\hline
\end{tabular}




\section{ANÁLISIS DE LA VALORACIÓN}

La valoración patrimonial de una localidad comienza con el cálculo del valor de cada grupo de criterios. Con la baremación expuesta en el apartado anterior, los valores máximos que pueden obtenerse son de 40 puntos en cada uno de los grupos de criterios (científicos, potencialidad de uso y riesgos de deterioro).

En algunos modelos de valoración se utilizan coeficientes de peso para cada criterio, otorgándole de esta forma más influencia a unos parámetros que a otros. En el modelo de FOPALI todos los criterios tienen el mismo peso final, es decir, ninguno de ellos tiene mayor importancia que otro en el resultado final. Este modo de baremar, considerando cada grupo de criterios por separado, iguala la importancia de los diferentes componentes del valor patrimonial de una localidad. Un yacimiento paleontológico, por ejemplo, no tiene más valor científico por ser localidad tipo de una nueva especie que por tener un alto interés tafonómico. Que se destaque un aspecto sobre otro es más lógico en las publicaciones de los especialistas en cada campo que en los trabajos de los investigadores del patrimonio, que deben tomar en consideración la totalidad de características conjuntamente.

Por otro lado, el resultado final de la valoración de cada grupo de criterios se normaliza a valores entre 0 y 100 con el objeto de proporcionar valores relativos de más fácil comparación. Además, como cada uno de los tres grupos de criterios se valora por separado, la normalización elimina el sesgo que pudiera representar la diferencia de escalas en el baremo, debidas fundamentalmente a los distintos rangos de valores de los diferentes criterios.

Con todo, considerando las variables que nos señalan el valor científico, las que caracterizan su potencialidad de uso y las que consideran los riesgos de deterioro, se puede realizar una ponderación cuantitativa del valor patrimonial de cada localidad inventariada, obteniéndose una matriz de valoración patrimonial (Tabla 6). Cuando se realiza el estudio patrimonial de áreas concretas, los resultados plasmados en las matrices de valoración individual para cada localidad se pueden agrupar en forma de matriz general de comparación. De este modo, los diferentes yacimientos o afloramientos inventariados y valorados se pueden comparar entre sí mediante el uso de una matriz en la que se entrecruzan los valores de los criterios seleccionados con los distintos puntos de interés (Tabla 7). El resultado permite diferenciar los lugares más importantes desde el punto de vista científico, de su potencialidad de uso o incluso establecer cuáles son los que presentan un mayor riesgo de deterioro o desaparición.

Por último, se elabora un gráfico de síntesis patrimonial como el que se ofrece en la Figura 3. En él, los tres grupos de criterios de valoración quedan representados de forma clara: los científicos en las abscisas, los de potencialidad de uso en las ordenadas y el riesgo global para cada punto
Tabla 6. Modelo de matriz de valoración patrimonial para una localidad paleontológica. $\Sigma \mathrm{VC}$ : suma de la valoración de los criterios científicos. $\Sigma$ VP: suma de la valoración de la potencialidad de uso. $\Sigma$ VR: suma de la valoración de los riesgos de deterioro.

\begin{tabular}{|c|c|c|c|c|c|c|}
\hline CRITERIOS DE VALORACIÓN & $\mathbf{0}$ & 1 & 2 & $3 \mid 4$ & 5 & \\
\hline \multicolumn{7}{|l|}{ Abundancia de afloramientos similares } \\
\hline \multicolumn{7}{|l|}{ Localidad tipo } \\
\hline \multicolumn{7}{|l|}{ Paleodiversidad / Geodiversidad } \\
\hline \multicolumn{7}{|l|}{ Estado de conservación inmueble } \\
\hline \multicolumn{7}{|l|}{ Estado de conservación mueble } \\
\hline \multicolumn{7}{|l|}{ Interés tafonómico / genético } \\
\hline \multicolumn{7}{|l|}{ Interés geológico } \\
\hline \multicolumn{7}{|l|}{ Bioestratigrafía } \\
\hline \multicolumn{7}{|l|}{ Litoestratigrafía } \\
\hline \multicolumn{7}{|l|}{ Tectónica } \\
\hline \multicolumn{7}{|l|}{ Geomorfología } \\
\hline \multicolumn{7}{|l|}{ Utilidad para ilustrar procesos } \\
\hline \multicolumn{7}{|l|}{ Potencial científico } \\
\hline VALOR CIENTÍFICO & & & & & & $\sum V C$ (máx. 40) \\
\hline \multicolumn{7}{|l|}{ Grado de conocimiento o investigación } \\
\hline \multicolumn{7}{|l|}{ Valor histórico } \\
\hline \multicolumn{7}{|l|}{ Interés didáctico } \\
\hline \multicolumn{7}{|l|}{ Valor complementario } \\
\hline \multicolumn{7}{|l|}{ Proximidad a poblaciones } \\
\hline \multicolumn{7}{|l|}{ Número de habitantes en el entorno } \\
\hline \multicolumn{7}{|l|}{ Visibilidad } \\
\hline \multicolumn{7}{|l|}{ Accesibilidad } \\
\hline VALOR DE POTENCIALIDAD DE USO & & & & & & $\sum \mathrm{VP}$ (máx. 40) \\
\hline \multicolumn{7}{|l|}{ Riesgos por accesibilidad } \\
\hline \multicolumn{7}{|l|}{ Riesgos por visibilidad } \\
\hline \multicolumn{7}{|l|}{ Riesgos por proximidad a poblaciones } \\
\hline $\begin{array}{l}\text { Riesgos por el número de habitantes en el } \\
\text { entorno }\end{array}$ & & & & & & \\
\hline Usos del suelo & & & & & & \\
\hline Vertederos & & & & & & \\
\hline Edificaciones & & & & & & \\
\hline Explotaciones mineras & & & & & & \\
\hline Agrícola y ganadero & & & & & & \\
\hline Infraestructuras & & & & & & \\
\hline Grado de afección por el uso del suelo & & & & & & \\
\hline Vulnerabilidad ante el expolio & & & & & & \\
\hline Susceptibilidad ante el expolio & & & & & & \\
\hline Frecuencia de expolio & & & & & & \\
\hline Riesgos no antrópicos & & & & & & \\
\hline Fauna & & & & & & \\
\hline Flora & & & & & & \\
\hline Geodinámica externa & & & & & & \\
\hline Geodinámica interna & & & & & & \\
\hline VALOR DE LOS RIESGOS & & & & & & $\sum V R$ (máx. 40) \\
\hline
\end{tabular}


Tabla 7. Modelo de matriz general de comparación del valor patrimonial para un conjunto de localidades. $\Sigma$ VC: suma de la valoración de los criterios científicos. $\Sigma$ VP: suma de la valoración de la potencialidad de uso. $\Sigma$ VR: suma de la valoración de los riesgos de deterioro.

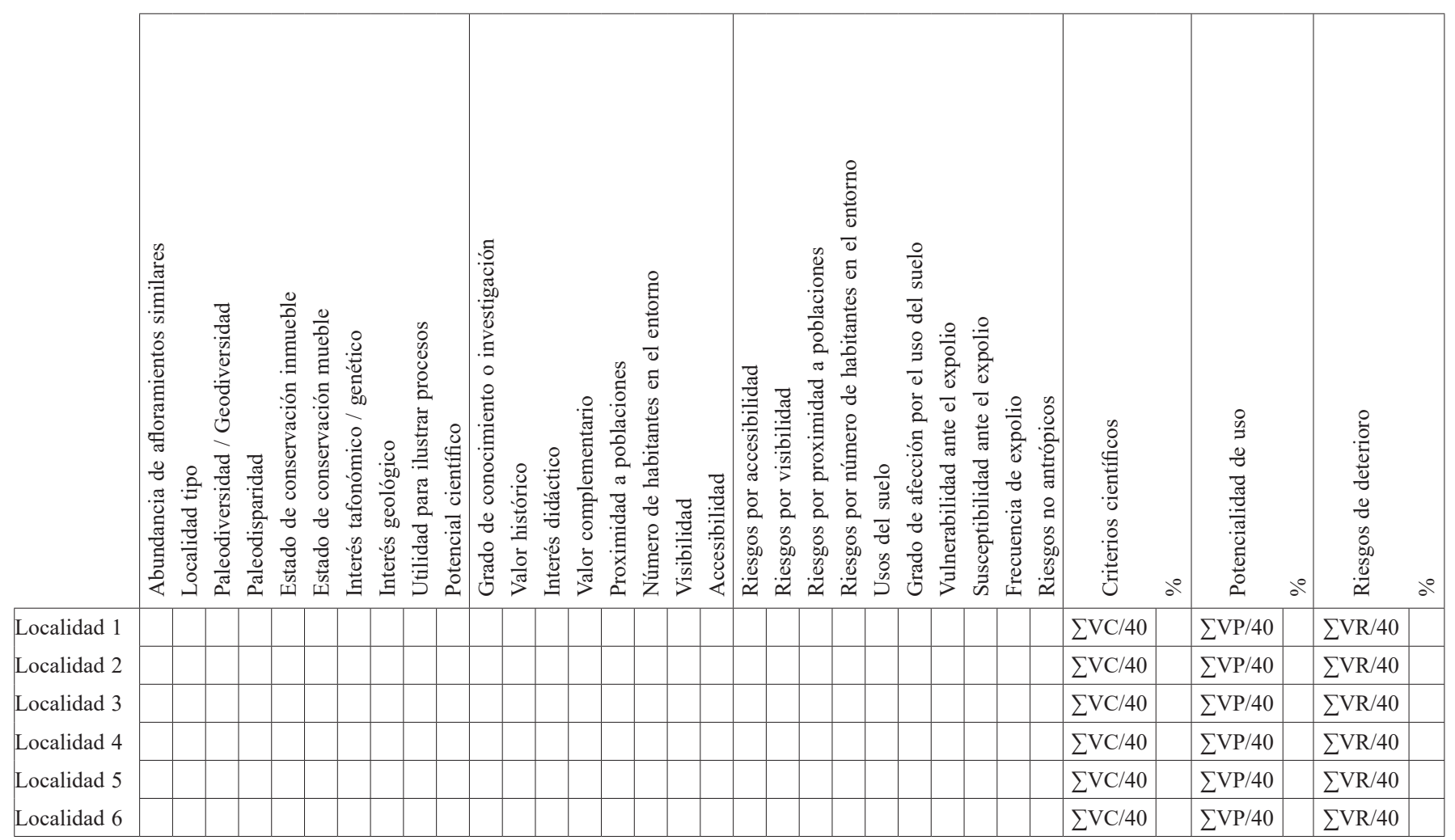

Síntesis de valoración patrimonial

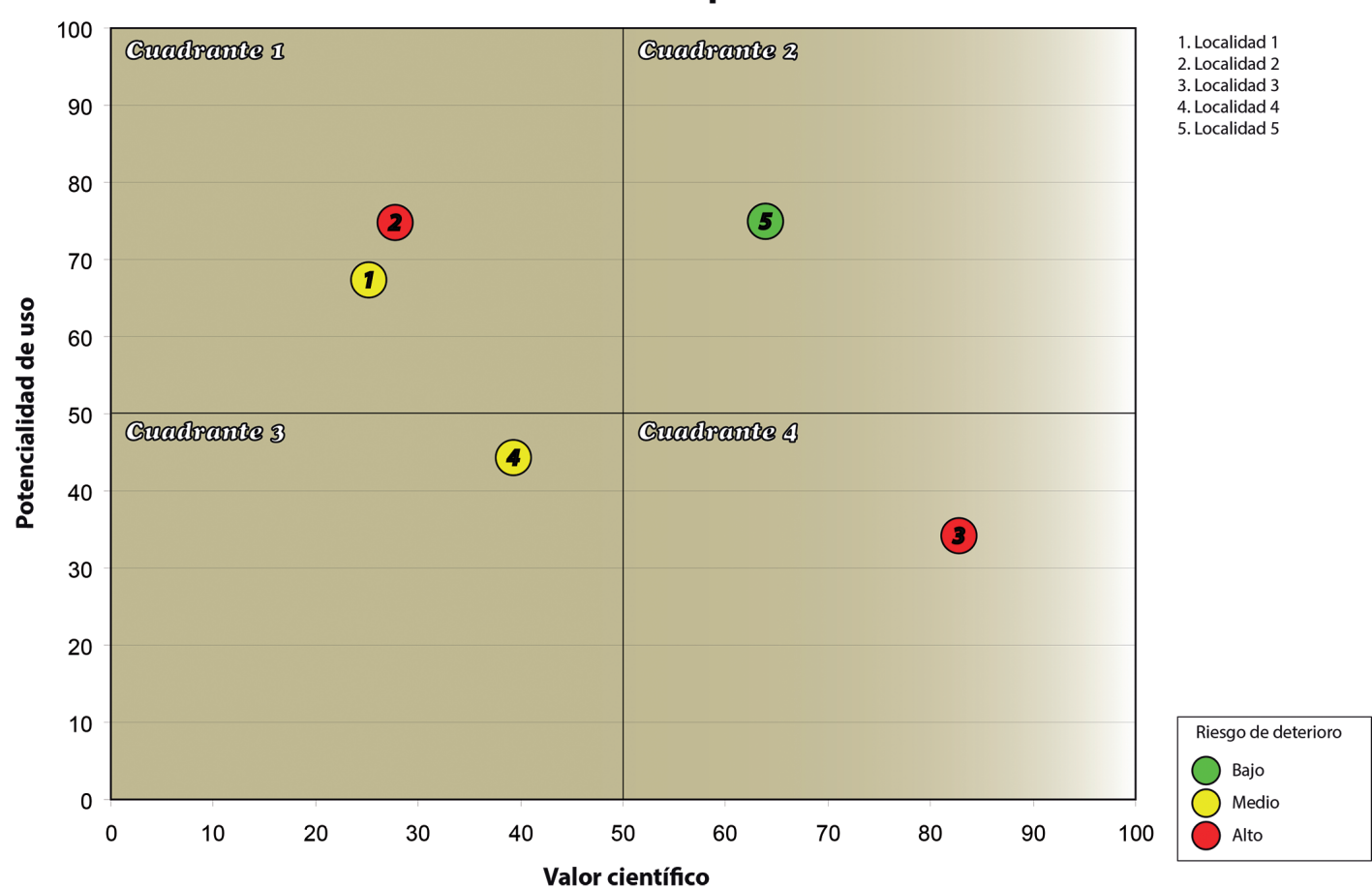

Figura 3. Ejemplo ficticio de gráfico de síntesis de valoración patrimonial de yacimientos. Localidad 1: Bajo valor científico, alto valor de uso, riesgo medio. Localidad 2: Bajo valor científico, alto valor de uso, riesgo alto. Localidad 3: Alto valor científico, bajo valor de uso, riesgo alto. Localidad 4: Bajo valor científico, bajo valor de uso, riesgo medio. Localidad 5: Alto valor científico, alto valor de uso, riesgo bajo. 
como un código de colores (verde para riesgos inferiores al $33 \%$, amarillo entre el 33 y el $66 \%$ y rojo para riesgos mayores que el 66\%).

Esta forma de representación ofrece varias ventajas. En primer lugar, resulta una forma clara y sencilla de exponer la información relevante sobre el patrimonio a los gestores del mismo. Cada localidad se sitúa en uno de los cuatro cuadrantes de la gráfica según su valor científico y su potencialidad de uso. De este modo, rápidamente se puede comprobar qué localidades poseen un mayor valor $\mathrm{y}$, atendiendo a su color, cuáles tiene un mayor riesgo de deterioro.

En segundo lugar, permite visualizar combinadamente el valor científico, la potencialidad de uso y el riesgo de deterioro y ordenar las diferentes localidades respecto a sus prioridades de gestión de forma intuitiva.

Por último, permite situar en contexto el patrimonio de un territorio concreto por comparación con los datos obtenidos en otros territorios: bastaría únicamente con añadir los puntos correspondientes en la gráfica.

\section{ALGUNOS RESULTADOS DE LA APLICACIÓN DE FOPALI}

El modelo de valoración expuesto en este trabajo y la estrategia general de FOPALI ha sido puesto a prueba en numerosas localidades del entorno del MUPE en la Comunidad Valenciana, así como en otras comunidades o en el extranjero. Esto nos ha permitido ir ajustándolo para optimizar su utilidad como herramienta de gestión.

La aplicación de la primera versión se realizó sobre el conjunto de los yacimientos del término municipal de Elche incluidos en la Carta Paleontológica de la Comunidad Valenciana (Sánchez-Ferris \& Montoya, 1995; SánchezFerris \& Fierro-Bandera, 2007). Poco tiempo después se llevó a cabo la valoración del patrimonio geológico y paleontológico del término municipal de Alicante, incluyendo, además de las localidades ya conocidas en la Carta Paleontológica, otros lugares de interés (SánchezFerris \& Fierro-Bandera, 2009).

Más recientemente, este modelo ha sido utilizado en un conjunto de yacimientos paleoictiológicos de la Cuenca de Lorca (Fierro-Bandera, 2015), así como en dos parajes naturales del término municipal de Elche: el Clot de Galvany y el Pantano (Sánchez-Ferris, 2015; SánchezFerris, 2019).

Por último, el modelo de FOPALI también ha sido utilizado en la caracterización de la relevancia patrimonial del LIG del arrecife messiniense de Santa Pola (Alicante) (Corbí \& Fierro, 2016; Corbí et al., 2017). En este último caso el modelo de FOPALI fue utilizado comparativamente frente al modelo del Inventario Español de Lugares de Interés Geológico (IELIG), modelo potenciado por el Instituto Geológico y Minero de España (IGME) y actualmente usado como referencia para la selección de enclaves de interés geológico en España. Los resultados de esta comparativa entre modelos ha ofrecido datos de gran relevancia sobre la utilidad de los mismos.

En el conjunto de estas actuaciones se han valorado un total de 61 localidades geológicas y paleontológicas obteniendo resultados que han sido reflejados en un Sistema de Información Geográfico.

\section{CONCLUSIONES Y UTILIDAD DEL MODELO}

FOPALI y su modelo de valoración, han sido concebidos como herramientas para la gestión patrimonial. De este modo, los gestores del patrimonio disponen de una ayuda en la toma de decisiones que impliquen una actuación sobre los bienes patrimoniales, una guía para priorizar racionalmente unos lugares frente a otros. Este modelo, desarrollado desde el Museo Paleontológico de Elche y la Fundación Cidaris dota de sentido a las actividades propias asociadas a un museo de paleontología, exteriorizando la gestión hacia los bienes inmuebles, fuertemente sometidos a una presión antrópica en el sureste peninsular.

Creemos que FOPALI forma parte de una estrategia planteada desde el sentido común. A pesar de ser un modelo basado en un concepto de patrimonio amplio (y realista), eso no implica la necesidad de conservarlo todo.

Somos conscientes de los maximalismos tradicionales desde los que resulta inviable la gestión del patrimonio: uno de ellos se basa en el conservacionismo a ultranza (patrimonio geológico es todo y por lo tanto todo merece ser conservado indefinida e indiscriminadamente), mientras que el otro extremo se basa en el provisionalismo a ultranza (el patrimonio geológico queda subordinado al interés del ser humano y por tanto su conservación es totalmente secundaria) (Pallí-Buxó, 1997).

Nuestra visión se basa en la búsqueda de un término intermedio basado, fundamentalmente, en el uso de una herramienta de valoración patrimonial y en la consideración de que todos los elementos geológicos forman parte del patrimonio, pero que sin embargo solo pretende conservar y proteger aquellos que muestren un mayor valor mediante el uso de dicha herramienta.

La aplicación del modelo de valoración patrimonial de FOPALI ha generado unos resultados altamente satisfactorios y útiles en todas las actuaciones en que ha sido puesto en funcionamiento. Estos trabajos previos han constituido un inmejorable banco de pruebas para el modelo presentado en este artículo.

Evidentemente, ningún sistema de valoración puede considerarse como definitivo. De hecho, estamos trabajando 
en la mejora de ciertos aspectos, como la inclusión de criterios relacionados con la valoración del paisaje o la aplicación de métodos estadísticos multivariantes que permitan análisis más detallados.

Por último, algunas de las bases teóricas del modelo de valoración presentado difieren de las del paradigma actual, recogido en gran parte de la legislación vigente. En un trabajo reciente (Corbí et al., 2017), se compara el método de FOPALI con el del Inventario Español de Lugares de Interés Geológico (IELIG), concluyendo que la elección de uno u otro modelo dependerá del objetivo y las características de la evaluación patrimonial que se desea llevar a cabo. El método del IELIG estaría más enfocado en la selección de las localidades de interés geológico más representativas de España, mientras que el de FOPALI se centra en determinar el orden de importancia de diferentes localidades de un área concreta de cara a una gestión eficiente.

El interés que ha guiado este trabajo no es otro que el de contribuir a la conservación del patrimonio geológico y paleontológico, y creemos firmemente que la discrepancia es como el arado que rotura las concepciones establecidas, permitiendo que las ideas se aireen y ofrezcan nuevos frutos.

\section{AGRADECIMIENTOS}

Queremos agradecer las sugerencias de los revisores y editores. Sus valiosos comentarios han permitido mejorar apreciablemente el manuscrito.

\section{REFERENCIAS}

Alcalá, L. 2002. Valoración patrimonial de los yacimientos de vertebrados de la Fosa de Teruel. In: El Patrimonio Paleontológico de Teruel (coords. Meléndez, G. \& Peñalver, E.). Instituto de Estudios Turolenses, Diputación de Teruel, 227-242.

Alcalá, L. \& Morales, J. 1994. Towards a definition of the spanish palaeontological heritage. In: Geological and Landscape Conservation (eds. O'Hallaran, D., Green, C., Harley, M., Stanley, M. \& Knill, J.). Geological Society, London, 57-61.

Ayala-Carcedo, F.J. 2000. Patrimonio natural y cultural y desarrollo sostenible: el patrimonio geológico y minero. In: Patrimonio Geológico y Minero en el Marco del Desarrollo Sostenible (ed. Rábano, I.). Colección Temas Geológico-Mineros, 31, 17-39.

Babin, C. 1992. Los yacimientos de fósiles, su protección y su interés cultural en algunos países de Europa. In: Conferencias de la Reunión de Tafonomía y Fosilización (coord. Fernández-López, S.). Editorial Complutense, 45-62.
Balanyá, J.C., Expósito, I. \& Díaz-Azpiroz, M. 2006. El Patrimonio Geológico: investigación, formación y ofertas universitarias. Pliocénica, 5, 17-25.

Barnosky, A.D., Carrasco, M.A. \& Davis, E.B. 2005. The impact of the species-area relationship on estimates of paleodiversity. PLoS Biol, 3, e266; doi: 10.1371/journal. pbio.0030266.

Becerra-Ramírez, R., Dóniz-Páez, F.J. \& González-Cárdenas, E. 2015. Bases metodológicas para la gestión de los volcanes del Campo de Calatrava (Ciudad Real) como patrimonio geomorfológico. In: Patrimonio Geológico y Geoparques. Avances de un Camino para Todos (eds. Hilario, A., Mendia, M., Monge-Ganuzas, M., Fernández, E., Vegas, J. \& Belmonte, A.). Cuadernos del Museo Geominero, 18, 91-96.

Braga, J.C. \& Villalobos, M. 2002. Propuesta de Estrategia Andaluza para la Conservación de la Geodiversidad. Consejería de Medio Ambiente, Junta de Andalucía, Departamento de Estratigrafía y Paleontología, Universidad de Granada, 105 pp.

Brilha, J. 2016. Inventory and quantitative assessment of geosites and geodiversity sites: a review. Geoheritage, 8 , 119-134; doi: 10.1007/s12371-014-0139-3.

Bruschi, V.M. \& Cendrero, A. 2005. Geosite evaluation: can we measure intangible values? Italian Journal of Quaternary Sciences, 18, 293-306.

Carcavilla-Urquí, L. 2009. Metodología para la Elaboración del Inventario de Lugares de Interés Geológico. Publicaciones del Instituto Geológico y Minero de España, Ministerio de Ciencia e Innovación, 36 pp.

Carcavilla-Urquí, L., López-Martínez, J. \& Durán-Valsero, J.J. 2007. Patrimonio Geológico y Geodiversidad: Investigación, Conservación, Gestión y Relación con los Espacios Naturales Protegidos. Serie Cuadernos del Museo GeoMinero, 7, 1-360.

Carcavilla-Urquí, L., Durán-Valsero, J.J. \& López-Martínez, J. 2008. Geodiversidad: concepto y relación con el patrimonio geológico. Geo-Temas, 10, 1299-1303.

Castillo-Martín, A. 1996. Peculiaridades y estrategias de conservación del patrimonio geológico. Geogaceta, 19, 195-197.

Castillo, C., Martín-González, E. \& Hernández, Z. 2000. Criterios para la valoración del patrimonio paleontológico de Canarias. Geotemas, 1, 305-308.

Castillo, C., Martín-González, E. \& Martín-Oval, M. 2001. Valoración del patrimonio paleontológico de Canarias: propuesta de Puntos de Especial Interés Paleontológico. Revista Española de Paleontología, № Extra, 105-115.

Cendrero, A. 1996a. El Patrimonio Geológico. Ideas para su protección, conservación y utilización. In: El Patrimonio Geológico. Bases para su Valoración, Protección, Conservación y Utilización. Ministerio de Obras Públicas, Transportes y Medio Ambiente, 17-27.

Cendrero, A. 1996b. Propuesta sobre criterios para la clasificación y catalogación del patrimonio geológico. In: El Patrimonio Geológico. Bases para su Valoración, Protección, Conservación y Utilización. Ministerio de Obras Públicas, Transportes y Medio Ambiente, 29-38. 
Cobos, A. 2004. Valoración patrimonial de los yacimientos de icnitas de dinosaurio de la provincia de Teruel. Geogaceta, 36, 191-194.

Corbí, H. \& Fierro, I. 2016. El patrimonio geocientífico del arrecife Messiniense de Santa Pola (sureste de España): comparación entre dos modelos de valoración patrimonial. IX Congreso Geológico de España, Huelva, 12 al 14 Septiembre.

Corbí, H., Fierro, I., Aberasturi, A. \& Sánchez-Ferris, E.J. 2017. Potential use of a significant geosite: the messinian coral reef of Santa Pola (SE Spain). Geoheritage, 1-15; doi: 10.1007/s12371-017-0268-6.

Criado-Boado, F. 1996. Hacia un modelo integrado de investigación y gestión del Patrimonio Histórico: la cadena interpretativa como propuesta. PH Boletín del Instituto Andaluz del Patrimonio Histórico, 4, 73-78.

De la Hera, A., Durán, J.J. \& Murillo, J.M. 2013. El patrimonio geológico de los humedales de Miguel Ibañez (Segovia). In: Patrimonio Geológico, un Recurso para el Desarrollo (eds. Vegas, J., Salazar, A., Díaz Martínez, E. \& Marchán, C.). Cuadernos del Museo Geominero, 15, 411-420.

Díaz-Martínez, E., García-Cortés, Á, \& Carcavilla-Urquí, L. 2013. Los fósiles son elementos geológicos y el patrimonio paleontológico es un tipo de patrimonio natural. In: Patrimonio Geológico, un Recurso para el Desarrollo (eds. Vegas, J., Salazar, A., Díaz Martínez, E. \& Marchán, C.). Cuadernos del Museo Geominero, $15,583-589$.

Eguiarte, L.A., Larson-Guerra, J., Núñez-Farfán, J., MartínezPalacios, A., Santos del Prado, K. \& Arita, H.T. 1999. Diversidad filogenética y conservación: ejemplos a diferentes escalas y una propuesta a nivel poblacional para Agave victoriae-reginae en el desierto de Chihuahua, México. Revista Chilena de Historia Natural, 72, 475-492.

Elizaga, E. \& Palacio, J. 1996. Valoración de puntos y/o lugares de interés geológico. In: El Patrimonio Geológico. Bases para su Valoración, Protección, Conservación y Utilización. Ministerio de Obras Públicas, Transportes y Medio Ambiente, 61-79.

Fierro-Bandera, I. 2008. FOPALI: Fósiles y patrimonio de Alicante. In: Paleontología y Medio Ambiente (ed. Navarro-Pedreño, J.). Universidad Miguel Hernández de Elche, Museo Paleontológico de Elche, Conselleria d'Educació Generalitat Valenciana, Grupo Marjal, 33-58.

Fierro-Bandera, I. 2010. Análisis y gestión del Patrimonio Geológico y Paleontológico en el entorno del Pantano de Elche. Memoria del Master Interuniversitario en Análisis y Gestión de Ecosistemas Mediterráneos, Especialidad de Gestión Ambiental, Universidad Miguel Hernández, Elche, 95 pp.

Fierro-Bandera, I. 2015. Caracterización patrimonial de los depósitos laminados de la Cuenca de Lorca. Ph.D. Thesis, Universidad Miguel Hernández, Elche, 659 pp.

Fierro-Bandera, I. \& Marín-Ferrer, J.M. 2008. Proyecto ICTIO. Fase II. Memoria inédita, Geserpal, Museo Paleontológico de Elche, Consejería de Cultura, Región de Murcia, $82 \mathrm{pp}$.
Fierro-Bandera, I. \& Sánchez-Ferris, E.J. 2007. Proyecto Paleo-Clot. Patrimonio Geológico y Paleontológico del Clot de Galvany. Memoria inédita, Museo Paleontológico de Elche, Concejalía de Medio Ambiente, Ayuntamiento de Elche, 114 pp.

Fierro-Bandera, I., Marín-Ferrer, J.M. \& Sánchez-Ferris, E.J. 2007. Proyecto ICTIO. Fase I: La Serrata (Lorca). Memoria inédita, Geserpal, Fundación Cidaris, Consejería de Cultura, Región de Murcia, 137 pp.

Fierro-Bandera, I., Marín-Ferrer, J.M. \& Navarro-Pedreño, J. 2009. Informe PALDES Niamey. Noviembre 2008. Informe inédito Proyecto PALDES-AECID, 62 pp.

Fuertes-Gutiérrez, I., Fernández-Martínez, E. \& GarcíaOrtiz, E. 2013. Propuesta de términos en castellano sobre conceptos relacionados con el riesgo de degradación del patrimonio geológico. In: Patrimonio Geológico, un Recurso para el Desarrollo (eds. Vegas, J., Salazar, A., Díaz Martínez, E. \& Marchán, C.). Cuadernos del Museo Geominero, 15, 195-206.

García-Cortés, Á. 2015. Dos inventarios sucesivos del patrimonio geológico en la Zona Cantábrica (noroeste de España): 1980-84 y 2014-15. Algunas consideraciones preliminares. In: Patrimonio Geológico y Geoparques, Avances de un Camino para Todos (eds. Hilario, A., Mendia, M., Monge Ganuzas, M., Fernández, E., Vegas, J. \& Belmonte, A.). Cuadernos del Museo Geominero, 18, 97-102.

García-Cortés, Á., Gallego-Valcarce, E. \& Palacio-Suárez, J. 1992. El Patrimonio Geológico/The Geological Heritage. Instituto Tecnológico GeoMinero de España, 23 pp.

García-Cortés, Á., Carcavilla-Urquí, L., Vegas-Salamanca, J. \& Díaz-Martínez, E. 2013. Algunos resultados del inventario de lugares de interés geológico de la Cordillera Ibérica. In: Patrimonio Geológico, un Recurso para el Desarrollo (eds. Vegas, J., Salazar, A., Díaz Martínez, E. \& Marchán, C.). Cuadernos del Museo Geominero, $15,379-388$.

García-Cortés, Á., Carcavilla-Urquí, L., Díaz-Martínez, E. \& Vegas-Salamanca, J. 2014. Documento Metodológico para la Elaboración del Inventario Español de Lugares de Interés Geológico (IELIG). Instituto Geológico y Minero de España, Ministerio de Economía y Competitividad, 64 pp.

Gómez, E. \& Morales, J. 2000. Inventario y valoración. In: Patrimonio Paleontológico de la Comunidad de Madrid (eds. Morales, J., Nieto, M., Amezua, L., Fraile, S., Gómez, E., Herráez, E., Peláez Campomames, E., Salesa, M.J., Sánchez, I.M. \& Soria, D.). Consejería de Educación, Comunidad de Madrid, 316-331.

Hayward, B.W. 2009. Protecting fossil sites in New Zealand. In: Notebooks on Geology, 49-64.

Junta de Andalucía. 2008. Estrategia Andaluza de Gestión Integrada de la Geodiversidad. Documento Borrador. Dirección General de Gestión del Medio Natural, Consejería de Medio Ambiente, Junta de Andalucía, 162 pp.

Lane, A., Janis, C.M. \& Sepkoski Jr., J.J. 2005. Estimating paleodiversities: a test of the taxic and phylogenetic methods. Paleobiology, 31, 21-34. 
Lipps, J.H. 1981. What, if anything, is micropaleontology? Paleobiology, 7, 167-199.

Luque, L. \& Alcalá, L. 2002. Valoración patrimonial del yacimiento paleontológico de Libros. In: El Patrimonio Paleontológico de Teruel (coords. Meléndez, G. \& Peñalver, E.). Instituto de Estudios Turolenses, Diputación de Teruel, 243-255.

Mancheño, M.A., Romero, G. \& Rodríguez-Estrella, T. 2003. Valoración e interés patrimonial del yacimiento paleontológico de la Sierra de Quibas (Abanilla, Murcia). In: Patrimonio Geológico y Minero y Desarrollo Regional (eds. Rábano, I., Manteca, I. \& García, C.). Instituto Geológico y Minero de España, 61-66.

Marín-Ferrer, J.M. 2008. El Museo Paleontológico de Elche: historia de una afición. In: Paleontología y Medio Ambiente (ed. Navarro Pedreño, J.). Universidad Miguel Hernández de Elche, Museo Paleontológico de Elche, Conselleria d'Educació Generalitat Valenciana, Grupo Marjal, 19-32.

Mediavilla, R., Santisteban, J.I. \& Vegas, J. 2013. Propuesta de dos nuevos lugares de interés geológico en el Neógeno de Palencia. In: Patrimonio Geológico, un Recurso para el Desarrollo (eds. Vegas, J., Salazar, A., Díaz Martínez, E. \& Marchán, C). Cuadernos del Museo Geominero, 15, 259-268.

Meléndez, G. \& Peñalver, E. (coords.). 2002a. El Patrimonio Paleontológico de Teruel, Instituto de Estudios Turolenses, Diputación de Teruel, 447 pp.

Meléndez, G. \& Peñalver, E. 2002b. Evaluación y sistematización. Interpretación de las gráficas. In: El Patrimonio Paleontológico de Teruel (coords. Meléndez, G. \& Peñalver, E.). Instituto de Estudios Turolenses, Diputación de Teruel, 429-443.

Meléndez, G., Bello, J., Delvene, G., Pérez-Urresti, I., Ramajo, J. \& Soria, M. 2004. El patrimonio paleontológico de Teruel: yacimientos de invertebrados jurásicos de Sierra de Arcos. Geogaceta, 36, 187-190.

Miranda-Ariz, J.M., Silvestre-Barrio, M. \& Pérez-Vicente, D. 2003. Estudio Arqueológico de Detalle para Gasoductos y Redes de Distribución. Memoria inédita, 130 pp.

Morales, J. 1996. El Patrimonio paleontológico. Bases para su definición, estado actual y perspectivas futuras. In: El Patrimonio Geológico. Bases para su Valoración, Protección, Conservación y Utilización. Ministerio de Obras Públicas, Transportes y Medio Ambiente, 39-51.

Morales, J., Azanza, B. \& Gómez, E. 1999. Spanish Palaeontological Heritage, Coloquios de Paleontología, $50,53-62$.

Morales, J., Gómez, E. \& Azanza, B. 2002. El patrimonio paleontológico español: marco legal, titularidad, gestión y conservación. In: El Patrimonio Paleontológico de Teruel (coords. Meléndez, G. \& Peñalver, E.). Instituto de Estudios Turolenses, Diputación de Teruel, 53-62.

Moreno-Benítez, M. 2002. Patrimonio cultural. Puesta en valor y uso. Una reflexión. Vector Plus, 20, 41-49.

Nieto-Albert, L.M. 2001. Geodiversidad: propuesta de una definición integrada. Boletín Geológico y Minero, 112, $1-20$.
Palacio, J. 2000. Patrimonio geológico: aspectos metodológicos. In: Jornadas sobre Patrimonio Geológico y Desarrollo Sostenible (coord. Palacio, J.). Ministerio de Medio Ambiente, Sociedad Española de Geología Ambiental y Ordenación del Territorio, 11-22.

Pallí-Buxó, L. 1997. Restauración del Patrimonio Natural: una visión desde la geología. XXXI Curso de geología práctica de Teruel, 1, 221-235.

Peñalver, E. 2002. Los Insectos Dípteros del Mioceno del Este de la Península Ibérica; Rubielos de Mora, Ribesalbes y Bicorp. Tafonomía y Sistemática. Universidad de Valencia, $550 \mathrm{pp}$.

Pesquero, D., Sánchez, B. \& Alcalá, L. 2002. Valoración patrimonial de los yacimientos pliocenos de la depresión de Sarrión. In: El Patrimonio Paleontológico de Teruel (coords. Meléndez, G. \& Peñalver, E.). Instituto de Estudios Turolenses, Diputación de Teruel, 257-268.

Rendón, A., Henao, A. \& Osorio, J. 2013. Propuesta metodológica para la valoración del patrimonio geológico, como base para su gestión en el Departamento de Antioquia - Colombia. In: Patrimonio Geológico, un Recurso para el Desarrollo (eds. Vegas, J., Salazar, A., Díaz Martínez, E. \& Marchán, C.). Cuadernos del Museo Geominero, 15, 467-476.

Romero-Sánchez, G. \& Iniesta-Sanmartín, A. 1999. Proyecto de estructuración del patrimonio paleontológico en la Región de Murcia. Memorias de Arqueología, 14, 11-26.

Salinas-Gutiérrez, J.L. 2003. Índices filogenéticos para la conservación: una discusión del método. Anales del Instituto de Biología de la Universidad Nacional Autónoma de México, Serie Zoología, 74, 21-34.

Sánchez de Posada, L.C., Arbizu, M. \& Truyols, J. 2006. Prefacio: Consideraciones acerca del Patrimonio Paleontológico de Asturias. Trabajos de Geología, 26, 63-70.

Sánchez-Ferris, E.J. 2004. Estudio de Impacto sobre el Patrimonio Paleontológico del Trazado del Ramal “Arteria a Santa Pola” (Elche-Santa Pola, Alicante). Memoria inédita, $92 \mathrm{pp}$.

Sánchez-Ferris, E.J. 2005. Estudio del Impacto sobre el Patrimonio Paleontológico del Trazado de la Ronda Suroeste de San Miguel de Salinas, Tramo CV $95-C V$ 941 (San Miguel de Salinas, Alicante). Memoria inédita, $66 \mathrm{pp}$.

Sánchez-Ferris, E.J. 2008. Valoración patrimonial: una herramienta de gestión. In: Paleontología y Medio Ambiente (ed. Navarro Pedreño, J.). Universidad Miguel Hernández de Elche, Museo Paleontológico de Elche, Conselleria d'Educació Generalitat Valenciana, Grupo Marjal, 101-120.

Sánchez-Ferris, E.J. 2015. Patrimonio geológico y paleontológico del término municipal de Elche: el Clot de Galvany y el Pantano. Ph.D. Thesis, Universidad de Valencia, Instituto Cavanilles de Biodiversidad y Biología Evolutiva, 517 pp.

Sánchez-Ferris, E.J. 2018. La paleontología en el marco legal de la Comunidad Valenciana. PH Boletín del Instituto Andaluz del Patrimonio Histórico, 94, 294-295. 
Sánchez-Ferris, E.J. 2019. Palaeontological heritage: protected vs. unprotected areas. The case of Clot de Galvany Municipal Natural Park and Elche reservoir surroundings. Spanish Journal of Palaeontology, (this volume).

Sánchez-Ferris, E.J. \& Fierro-Bandera, I. 2007. Proyecto FOPALI. Memoria de Ejecución. Memoria inédita, SERVEF, Fundación Cidaris, 18 pp.

Sánchez-Ferris, E.J. \& Fierro-Bandera, I. 2009. Documentación del Patrimonio Geológico y Paleontológico del Término Municipal de Alicante: FOPALI Alicante (Fase I). Memoria inédita, Fundación Cidaris, Ayuntamiento de Alicante, $527 \mathrm{pp}$.

Sánchez-Ferris, E.J. \& Montoya, P. 1995. El patrimonio paleontológico valenciano y su protección: la Carta Paleontológica de la Comunidad Valenciana. Cidaris, 7, 49-54.

Sánchez-Ferris, E.J., Fierro-Bandera, I. \& Díaz-García, L. 2009. FOPALI Pantano Fase I. Documentación del Patrimonio Geológico y Paleontológico del Entorno del Pantano de Elche. Memoria inédita, Fundación Cidaris, Ayuntamiento de Elche, 83 pp.

Sánchez-Ferris, E.J., Fierro-Bandera, I., Marín-Ferrer, J.M. \& Navarro-Pedreño, J. 2010. FOPALI Alicante (Phase I): the geological and paleontological heritage of the municipality of Alicante (Spain). Geoevents, Geological Heritage and the Role of the IGPC. First Meeting of ProGEO Regional Working Group SW Europe, Caravaca de la Cruz (Murcia). Sánchez-Ferris, E.J., Fierro-Bandera, I., AberasturtiRodríguez, A., Navarro-Pedreño, J. \& Marín-Ferrer, J.M. 2014. Introducción al patrimonio geológico y paleontológico del Paraje Natural Municipal del Clot de Galvany (Elche, Alicante). Cidaris, 32, 5-19.

Santos-Cubedo, A. 2018. Marco legal del patrimonio paleontológico en la Comunidad Valenciana. PH Boletín del Instituto Andaluz del Patrimonio Histórico, 94, 299300 .

Schindel, D.E, 1980. Microstratigraphic sampling and the limits of paleontological resolution, Paleobiology, 6, 408-426.

Vegas, J., Channing, A., Anderson, C.L., Pais, J., Santos, A. \& Hernández, M.V. 2013. Los fósiles vegetales de la Caldera de Taburiente: investigación, geoconservación y divulgación del patrimonio paleontológico en la Isla de la Palma. In: Patrimonio Geológico, un Recurso para el Desarrollo (eds. Vegas, J., Salazar, A., Díaz Martínez, E. \& Marchán, C.). Cuadernos del Museo Geominero, 15, 353-360.

Villalobos, M., Braga, J.C., Guirado, J. \& Pérez-Muñoz, A.B. 2004. El inventario andaluz de georrecursos culturales: criterios de valoración. De Re Metallica, 3, 9-21. 